\title{
The stiffness of living tissues and its implications for their engineering
}

Carlos F. Guimarães ${ }^{1,2,3}$, Luca Gasperini ${ }^{1,2}$, Alexandra P. Marques ${ }^{1,2,3}$ and Rui L. Reis ${ }^{1,2,3 *}$

13B's Research Group - Research Institute on Biomaterials, Biodegradables and Biomimetics, University of Minho, Headquarters of the European Institute of Excellence on Tissue Engineering and Regenerative Medicine, Guimarães, Portugal.

${ }^{2}$ Life and Health Sciences Research Institute, 3B's Research Group on Biomaterials, Biodegradables and Biomimetics - Portuguese Government Associate Laboratory, University of Minho, Braga and Guimarães, Portugal.

${ }^{3}$ The Discoveries Centre for Regenerative and Precision Medicine, University of Minho, Guimarães, Portugal.

*e-mail: rgreis@i3bs.uminho.pt

\section{Web summary}

The complexity of biological tissue presents a challenge for engineering of mechanically compatible materials. Guimarães and colleagues discuss how understanding tissue stiffness, from extracellular matrix and single cell components to bulk tissue, facilitates the engineering of materials with life-like properties.

\begin{abstract}
The past 20 years have witnessed ever-growing evidence that the mechanical properties of biological tissues, from nanoscale to macroscale dimensions, are fundamental for cellular behaviour and consequent tissue functionality. This knowledge, combined with previously known biochemical cues, has greatly advanced the field of biomaterial development, tissue engineering and regenerative medicine. It is now established that approaches to engineer biological tissues must integrate and approximate the mechanics, both static and dynamic, of native tissues. Nevertheless, the literature on the mechanical properties of biological tissues varies widely in methodology and the available data are widely dispersed. This Review gathers together the most important data on the stiffness of living tissues and discusses the intricacies of tissue stiffness from a materials perspective, highlighting the main challenges associated with engineering life-like tissues and proposing a unified view on this as yet unreported
\end{abstract}


topic. Emerging advances that might pave the way for the next decade's take on bioengineered tissue stiffness are also presented, and differences and similarities between tissues in health and disease are discussed, along with various techniques for characterizing tissue stiffness at various dimensions from the cell to the organ level.

\section{[H1] Introduction}

Materials engineering involves the design or tuning of the structure of a material to produce a set of desired properties ${ }^{1}$. Living tissues are essentially materials engineered by nature itself to have a specific structure that affects cell properties and drives all consequent biological events. Tissue engineering tries to replicate this feat by designing the structure of a material to recapitulate a predetermined cell response.

When tissue engineering arose, more than 25 years ago, stiffness was already a term mentioned in the literature ${ }^{2}$. In the beginning, the premise was simple: a tissue substitute must be biomechanically able to fulfill the functions of the tissue it replaces and, as such, should have similar mechanics to the native tissue. Hard scaffolds began to be employed to engineer bone-like structures and hydrogels for soft tissue structures, which were combined with specific biochemical cocktails that could direct the behaviour of cells on these structures, which simply served the purpose of support. However, this paradigm shifted with the understanding that the stiffness of surfaces, independently of their shape, could be detected and responded to by cells ${ }^{3}$.

The ripples of this discovery are still reverberating throughout diverse fields of research, but it truly revolutionized tissue engineering as the supremacy of biochemical cues in driving cellular behaviour began to be questioned. Currently, when considering the stiffness of engineered constructs comprising cells on a three-dimensional (3D) support, one must think not only of its biomechanical integration with host tissue but also of cell mechanostimulation.

From adhesion to differentiation, the most relevant cellular events from early embryogenesis onwards ${ }^{4}$ are all, in some way, affected by tissue stiffness. As such, any modern tissue-engineering strategy has to consider the stiffness of the native biological tissue, as well as the implications of this stiffness for the behaviour of resident cells. These factors require not only bulk material analysis but also an understanding of the microscale and nanoscale domains within which the native extracellular matrix (ECM) components function in vivo. Moreover, cells themselves have a characteristic stiffness, 
which is a consequence not only of their interaction with the surrounding microenvironment but also of their biological and/or genetic status. For example, cancer cells frequently have altered (either increased or decreased) stiffness ${ }^{5}$. If tissue stiffness was initially considered a simple concept, it is now undeniably worthy of thorough and integrative study.

The Review brings together these topics using an approach that aims to be as interdisciplinary as the field of tissue engineering itself. After a brief overview of what stiffness is and how the mechanical properties of living tissues are measured, we consider each component in turn, starting with the smallest - ECM molecules and single cells - and continuing up to bulk living tissues and organs, which are compared and discussed from a biomaterials perspective. Finally, we outline the main avenues to follow when attempting to engineer life-like tissues, emphasizing the most recent advances in time-changing mechanics and identifying the main challenges for the future

- the questions that must be answered to enable tissue stiffness to be fully decoded and manipulated.

\section{[H1] The concept of stiffness}

The mechanical properties of a material — most notably its stiffness - relate to loads and deformations; that is, the forces exerted on the material and the resulting changes in its shape. To fully understand the stiffness of living tissues, one has first to explore these underlying concepts. The stiffness of a structure derives from the following two premises: first, that when a structure is exposed to a certain load, it will deform; and second, that the ratio between this load and the consequent deformation yields the stiffness of the structure, meaning how much load is necessary to achieve a certain deformation ${ }^{6}$. Although there is no absolute definition of what constitutes a 'stiff' or 'soft' material, rubber and foodstuffs are generally considered soft materials, wood and plastics are of intermediate stiffness, and steel is among the stiffest commonly encountered materials. Clearly, the load necessary to deform a stiff material, such as steel, will be far higher than that required to similarly deform a softer material such as wood or rubber.

The stiffness of materials commonly used in manufacturing is far higher than that of human tissues or organs, including the stiffness of materials employed specifically because of their deformability, such as the plastics used in ketchup bottles. The vast majority of industrial plastics (such as polypropylene, nylon or polyethylene) 
have elastic moduli in the range of 0.2-5.0 GPa, higher than that of all biological tissues except bone. By contrast, the stiffness of some foodstuffs is comparable to that of tissues: the elastic moduli of pannacotta are in the $100 \mathrm{~Pa}-1 \mathrm{kPa}$ range $\mathrm{e}^{7,8}$, gummy bears and bananas are between $50 \mathrm{kPa}$ and $100 \mathrm{kPa}$, an apple is about $1 \mathrm{MPa}$ and a carrot is around $7 \mathrm{MPa}^{9,10}$. Similarly, from a biological perspective, fat is clearly far softer than muscle tissue, which itself is far softer than bone (Fig. 1). Naturally, the stiffness of a tissue can be quantified and precisely analyzed but, despite the term being widely mentioned in the biomedical field, analyses of tissue stiffness are sometimes insufficiently detailed.

Stiffness is a general structural property that depends not only on the material itself but also on its amount and distribution (shape). For example, the hollow nature of bones confers an increased stiffness-to-weight ratio. During compression or extension (stretching) of a material, the whole cross-sectional area of the material equally sustains the stress, whereas during bending or torsion the material furthest away from the midpoint or centre line sustains most of the stress. For this reason, structural construction elements often have T-shaped or L-shaped cross-sectional shapes, which maximize their stiffness while minimizing the weight and amount of material used. Moduli and stiffness are intimately related concepts and therefore frequently used as synonyms. However, stiffness is a property of a structure, whereas moduli describe the properties of the material composing that structure. As such, various moduli relating to the intrinsic elastic properties of materials ${ }^{6}$ are reflected in the stiffness of the final structure. These moduli are derived from mathematical conversions of load versus deformation relationships obtained from standardized tests on samples of a standardized size and shape (Box 1).

For example, Young's modulus $(E)$ can be calculated by subjecting a material to uniaxial stress resulting from compression or extension and measuring elastic (that is, reversible) deformation (strain) in the linear region of the stress-strain curve:

$$
E \equiv \frac{\sigma(\varepsilon)}{\varepsilon}=\frac{F / A}{\Delta L / L_{0}}=\frac{F L_{0}}{A \Delta L}
$$

where $\sigma$ is uniaxial stress (force per unit surface); $\varepsilon$ is strain; $F$ is the force exerted on an object (uniaxial stress); $A$ is the cross-sectional area perpendicular to the applied force; $\Delta L$ is the amount by which the length of the object changes ( $\Delta L$ has a positive value for a stretched material and a negative value for a compressed material); 
and $L_{0}$ is the original length of the object. Thus, the axial stiffness $(k)$ of a longitudinal structure such as a beam can be calculated as:

$$
k=\frac{E A}{L_{0}}
$$

It is worth noting that the above equations assume a linear relationship between strain and stress (that is, Hooke's law). In real-life scenarios this assumption might not hold for all levels of strain, particularly for polymers. The proportional limit represents the maximum stress at which stress and strain are proportional, and varies for different materials. Below this limit, the chemical bonds between atoms in the material stretch when under load but will recover completely when the load is released. Above this limit, the bonds will break and slip past each other, leading to non-proportionality. Therefore, the elastic modulus is typically measured at low strain values $(0.2 \%)^{11,12}$. Young's modulus is one of the most common measures of intrinsic material stiffness. Because it is independent of structure, Young's modulus is widely used to characterize the stiffness of both manufactured materials and tissues (Fig. 1a,b). However, in addition to uniaxial stress, biological tissues might also be subjected to deformations resulting from shear forces (Fig. 1c). The shear modulus $(G)$ is calculated similarly to Young's modulus in that stress (force per unit area) is divided by strain. However, whereas for Young's modulus stress and strain are both normal to the crosssectional area, for the shear modulus they are parallel and associated with an angular change. In isotropic materials, $E$ and $G$ are related to each other through Poisson's ratio $(v)$, given by the following equation:

$$
E=2 G(1+v)
$$

For many common materials, Poisson's ratio is similar to that of incompressible rubber $(v=0.5)$; thus $E$ is frequently approximated to $\sim 3 G$. Together, the shear and elastic moduli represent the properties of materials under two different types of load, which might suffice to give a general idea of the rigidity of various biological tissues. However, different loads can be simultaneously applied to the same tissue: for example, cartilaginous tissues are routinely subjected to both compressive and shear deformations ${ }^{13}$. Furthermore, such complex loads can cause materials to deform in multiple ways, such as torsion and bending (Fig. 1d). In the case of bending, one side of the sample is subjected to compressive stress and the opposite side to tensile stress. The mineralized constituent of bone, for example, as for other brittle materials, is highly resistant to compressive stress but not so much to tensile forces; consequently, bending 
can result in fracture. As such, it is important to consider different types of stress even in the same tissue. The most relevant types of stress in tissue engineering are those that are similar to physiological loads.

Furthermore, it is important to outline that some of these mechanical relationships do not apply directly to most biological tissues. Equation (3), for example, applies only to isotropic materials but is frequently erroneously used for anisotropic materials (those whose mechanical characteristics differ according to the direction of measurement). Similarly, biological tissues have very complex, anisotropic structures (in which many types of matter are present and unevenly distributed) that differ greatly from the typically isotropic, continuum structures used in manufacturing (in which few types of matter are present and are continuously distributed in the containing space). As such, even though it is useful to discuss the relationships that exist between mechanical concepts at this simple level, these will, in practice, be affected by length scale, anisotropy, spatial variations, nonlinear behaviour and other characteristics of biological tissues, discussed further in this article.

Viscoelasticity is another important point to discuss, as the natural response of all solid materials to stress is not purely elastic but also has a viscous component, which is also the case with living tissues. When elastic and viscous components are both prominent in defining the mechanical behaviour of a material, the material is generally referred to as viscoelastic. This type of material can only be fully characterized by timedependent tests, which apply strain and measuring the required force as a function of time (stress relaxation) or apply stress and measuring strain as induced changes in shape (creep), or through dynamic mechanical analysis (DMA) ${ }^{14}$. In DMA, loads are applied and released cyclically, often at varying frequencies or temperatures, which facilitates measurement of the viscoelastic response of a material during faster deformations than those derived by creep and stress relaxation tests.

The viscoelastic response of a material is used to derive the dynamic or complex modulus, which is usually represented by storage and loss moduli. For uniaxial forces, the storage modulus $\left(E^{\prime}\right)$ represents the elastic, instantaneous and reversible response of the material: deformation or stretching of chemical bonds while under load stores energy that is released by unloading. The loss modulus $\left(E^{\prime \prime}\right)$ represents the viscous time-dependent response of the material and is related to irreversible rearrangements and remodeling of their internal structure, such as the slippage of polymer chains past each other. Similarly, for deformations resulting from shear forces, the shear storage 
$\left(G^{\prime}\right)$ and shear loss $\left(G^{\prime \prime}\right)$ moduli ${ }^{15}$ are frequently evaluated by rheology and oscillatory experiments (Table 1). As biological tissues generally have viscoelastic responses, these tests are extremely relevant in the biomechanical field.

\section{[H2] Time scale}

Some materials exhibit different responses when deformed at different speeds. For example, the toy Silly Putty is made of a silicone blend that exhibits a strong elastic response at high rates of deformation and a strong viscous or liquid-like response at low rates of deformation ${ }^{16}$. Mechanical tests need to take into consideration the potential for time dependency. A frequency sweep, for example, is commonly performed in dynamic tests to evaluate the response of the sample to different speeds of deformation. During these tests, the storage modulus typically increases with rising deformation frequency; that is, the elastic response of these materials increases with the speed of deformation. Thus, deformation speed can play a crucial part in defining the response of a material under load ${ }^{17,18}$. Particularly slow speeds of deformation can approximate a static system. Some mechanical tests can be performed either under such quasi-static or dynamic conditions $^{19}$.

Three important consequences can be derived from these considerations: first, that under quasi-static conditions, the time-dependent behaviour (viscoelasticity) of materials is simplified because the behaviour of the material corresponds to its 'associated' elasticity ${ }^{20,21}$; second, that quasi-static testing cannot provide information about the viscous and/or elastic responses that take place under dynamic loads namely, those resembling physiological deformations; and third, that substantial differences can be expected to occur at distinct load time scales, and as such, direct comparisons between scales are inadvisable (Box 1).

\section{[H2] Spatial scale}

Differences between the macroscopic properties and bulk properties of a material, and the effects of surface microscale or nanoscale features should also be considered. Surfaces can behave very differently to bulk material: according to the Nobel laureate Wolfgang Pauli, "God made the bulk; surfaces were invented by the devil."22. Atoms on the surface of a solid are in an anisotropic environment because they can interact with other atoms on the surface, in the bulk below, and in liquid or gaseous phases. The macroscopic definition of Young's modulus as an intrinsic material property that is 
independent of size sometimes fails at nanoscale or microscale dimensions, where the moduli of materials might not only differ but also can become size-dependent ${ }^{23}$. As such, assessments of the mechanical properties of biological materials should examine the bulk tissue as well as its constituents at nanoscale or microscale dimensions because not only are the moduli themselves likely to be different at different scales but also because at these smaller dimensions cells sense the material and individually respond to its mechanical characteristics ${ }^{24}$. These intricacies, together with the wide range of available investigative techniques, make the mechanical characterization of biological tissues highly complex, and suggest that standardization could lead to improvement (Table 1, Box 1).

Considerable research effort has focused on ways to homogenize the microscale properties of a material and thereby to derive those ruling at the macroscale.

Approaches such as computational homogenization are based, in brief, on defining a representative volume element of smaller (usually microscale) dimensions than the complete structure, which can then be used to model its governing macroscale behaviour $^{25,26}$. Within the context of tissue mechanical properties, such an approach involves first defining the microscale components that govern the mechanical properties of the tissue, such as the elastin and collagen fibres of the arterial wall. Second, the properties of these components can be assessed by a technique that probes their mechanics at the same scale, such as atomic force microscopy (AFM) indentation. Finally, the characteristics of the small-scale elements can be used to mathematically model their macroscale mechanics, which in this example are those of the whole arterial wall ${ }^{27}$. Similarly, complex scaffolds used in tissue engineering can also be designed by modeling the individual components of their architecture, which are then combined to find best-fit shapes that closely approach the mechanical properties of biological tissues $^{28}$.

In the next few sections we critically explore the properties of different tissues in terms of their static and dynamic mechanics, beginning with the microscale and nanoscale domains of biological structures and continuing in size order up to the macroscale level.

\section{[H1] Tissue mechanics at increasing scales}

To understand the mechanical complexity of an organ or a complete functional tissue, one must first consider its smallest constituents. A biological tissue is fundamentally 
composed of ECM and cells, which coexist in a delicate synergy: the ECM is deposited by cells, which strongly interact with it. Beyond the fact that ECM structures themselves have inherent mechanical properties, they are also involved in cellular signaling (derived from both biochemical cues and mechanotransduction events), which has consequences for the mechanical properties of cells ${ }^{29,30}$. ECM mechanics and cell mechanics are intimately intertwined and together contribute to overall tissue behaviour. As such, one must not only consider the individual properties of ECM and cells but also understand the development of functional biological tissues. Multicellular structures require analyses of the locations where cell-cell connections are established and how these cellular structures bind to the ECM they produce and thereby create the basal mechanical framework of biological tissues. Here, we use a sequential approach, starting with an analysis of ECM and cells and gradually integrating their mechanical behaviour, informed by remarkable insights from developmental biology studies.

\section{[H2] Extracellular matrix components}

The type, concentration and organization of ECM components (which are all fabricated by cells) deeply affect the mechanical properties of both healthy and diseased tissues (discussed further in the 'Abnormal tissue states' section). The literature on mechanical properties of individual ECM components is scarce, and most reported analyses were done on bulk tissue samples or on structures (such as hydrogels) engineered from ECM components ${ }^{31}$. Nonetheless, several well-known ECM components occur in many different tissues and are critical for homeostasis, healing and regeneration, namely proteins (such as collagen, elastin, fibronectin, laminin, tenascin, vitronectin) and glycosaminoglycans (GAGs) ${ }^{32}$. Each of these components has distinct functions and, naturally, different mechanical properties (Table 2).

[H3] Collagen. Collagen is the most abundant ECM component and is consequently the one that has been most thoroughly explored in terms of its mechanics. From single molecules to fibrils, collagen structures have elastic moduli in the GPa range ${ }^{33,34}$. The final contribution of these structures to the bulk mechanics of living tissues depends mainly on collagen abundance and organization. Collagen exists in 28 currently known types, which act not only as structural proteins but also have other functions such as cellular adhesion that are similarly important for overall ECM assembly and its consequent tissue mechanics (reviewed elsewhere) ${ }^{35,36}$. Collagen structures and specific 
domains within the molecule can also be mineralized, leading to the formation of truly stiff ECMs such as those present in bone ${ }^{37}$.

Interestingly, some tissues are soft at low strains owing to a random collagen fibre orientation. Upon stretching, the collagen molecules align and become an extremely stiff network, which shifts the Young's modulus of the tissue towards that of the collagen fibres themselves ${ }^{38-40}$. Thus, tensile deformation leads to a J-shaped stressstrain curve in which deformation can initially be obtained by relatively low stress, whereas much higher stress is needed to reach higher deformations. For example, it doesn't take much force to pinch and pull a few millimeters of skin, but further deformation requires a much higher (and more painful) force. Once the force is released, skin returns to its original shape.Thus, biological tissues have the capacity to limit the deformation resulting from high levels of strain owing to reorganization of their structural fibres (mainly collagen), which gradually increases tissue stiffness and prevents damage from excessive strain. As such, it is important to characterize the moduli of tissues at both high and low strain levels. An attempt to engineer a life-like tissue based on its low-strain stiffness would probably fail to fulfil its function of preventing high-strain damage. Conversely, a tissue engineered to reflect only the highstrain modulus would be too stiff to have the compliant mechanics required for limb movement. Thus, biological tissues with a J-shaped stress-strain curve should be substituted for by materials with similar J-shaped curves ${ }^{41}$.

[H3] Elastin. Elastin, so named for its elasticity-enhancing capabilities, is another ECM component that is intimately related to collagen in terms of its contribution to tissue mechanics. Both collagen and elastin form fibrous networks that are intimately interwoven but remain structurally independent from each other. Elastin is frequently present in organs such as skin, lungs, and bladder but its most important function relates to blood vessels, namely arteries, where specific combinations of collagen and elastin determine the mechanical properties of the arterial wall and consequently regulation of both blood pressure and blood flow ${ }^{42}$. Importantly, elastin shows a notably high linear elastic extension. Thus, the addition of elastin reduces the elastic modulus of a tissue, and as such leads to a more compliant (easier to deform) structure. This effect is accounted for by the two orders of magnitude difference between the elastic moduli of collagen and elastin fibres (Table 2). 
The main function of hydrated elastin is to elastically stretch and contract, thereby acting as the driving force of elastic tissue recoil upon release of the force that caused the deformation ${ }^{43,44}$. The interplay of elastin and collagen leads to J-shaped stress-strain curves that show a high initial linear elastic extension, owing to the alignment of elastin's disordered structure (entropic), with linear behaviour at increased deformations owing to the molecular stretching of collagen fibres (enthalpic). In practical terms, increasing the elastin:collagen ratio leads to a decrease in overall tissue stiffness and an increase in its deformability and recoil, which can be employed in the development of elastic tissue-engineering scaffolds ${ }^{45}$. By contrast, a decreased elastin:collagen ratio has the opposite effects, as observed in several arterial conditions ${ }^{46}$.

[H3] Other ECM molecules. GAGs are also highly represented across distinct tissues, but their mechanics are poorly understood. In part, this lack of investigation could be due to their apparently minor contribution to the tensile-like moduli of tissues compared with that of ECM components such as collagen ${ }^{47}$. Nevertheless, GAGs are fundamental for water retention, shock absorption, lubrication and tissue viscoelasticity, properties that make them extremely important for the biomechanics of tissues such as cartilage, specifically its bulk compressive stiffness ${ }^{48}$.

In fact, the mechanical contribution of GAGs in articular cartilage is highly dynamic. Aggrecan, one of the main cartilage GAGs, can have distinct mechanical contributions depending on the loading conditions. Upon quasi-static loading, both electrostatic and steric interactions are responsible for the mechanical function of GAGs in cartilage, whereas under dynamic load (such as during running), solid-fluid interactions (that is, between GAGs and the interstitial fluid within cartilage) become the main contributor. These interactions, also known as poroelasticity, lead to cartilage interstital fluid pressurization and self-stiffening of cartilage with increasing loading frequencies ${ }^{49}$.

Fibronectin, another common component of the ECM in various tissues, also has an interesting role in tissue mechanics. Softer than most fibrillar ECM structures, fibronectin can be stretched by cell-generated tension and is able to extend more than eightfold before $50 \%$ of the fibres will experience rupture ${ }^{50}$. Furthermore, fibronectin fibre stiffening leads to an increase in $E$ of up to $3.5 \mathrm{MPa}$ (Table 2), a process accompanied by a force-dependent exposure of cryptic binding sites, which leads to 
changes in cell behaviour ${ }^{50}$. This evidence indicates a highly dynamic synergy between cell and fibronectin mechanics, which has also been shown to contribute prominently to the mechanical driving of tissue development ${ }^{51}$.Collagen, fibronectin and many other ECM components interact directly with cells, which not only synthesize but also remodel and adhere to them. The interaction is mutual: cells both create and influence the ECM components that drive tissue mechanics, which in turn regulate the behaviour of cells. Thus, it is easy to understand how small defects in ECM molecules might lead to devastating diseases such as osteogenesis imperfecta (brittle bone disease) ${ }^{52}$, junctional $^{53}$ and dystrophic ${ }^{54}$ epidermolysis bullosa (severe blistering of the skin), as well as Ehlers-Danlos syndrome collagenopathies (widespread connective tissue fragility, including life-threatening vascular instability $)^{55,56}$.

\section{[H2] Cellular mechanics}

The mechanical properties of cells (as well as their shape ${ }^{57}$ ) are closely intertwined with their behaviour. Only a few hours after fertilization, the mechanical properties of the oocyte already dictate its viability potential ${ }^{4}$. In 2007, the publication of a pivotal review entitled "The cell as a material" 58 for the first time considered cells as a material in their own right with characteristic mechanical properties that could be investigated using distinct techniques, one of the most important of which was AFM indentation. Overall, cells are soft entities; most have bulk elastic moduli in the $0.1-10.0 \mathrm{kPa}$ range, which hardly varies with cell type (Table 3). However, some variability-generating details require further discussion.

Firstly, cells (like tissues) are heterogeneous. Despite the softness of whole cells, certain cellular constituents, namely cytoskeleton fibres, have elastic moduli in the GPa range ${ }^{59}$. The contribution of these fibres to the mechanics of cells varies with the type of load applied. Intermediate filaments, actin filaments and microtubules (in order of increasing stiffness) respond differently to distinct types of deformation. Microtubules and actin filaments show substantial resistance to compressive forces, whereas intermediate filaments are best able to endure tensional loads ${ }^{60}$. Furthermore, some cytoskeleton fibres (such as microtubules and actin filaments) have a polarized molecular structure that enables them to act as molecular motors, which leads to a further level of mechanical complexity. Actin filaments, which dictate cell shape and consequently direct events ranging from motility to growth and differentiation, are frequently complexed with myosin to form a contractile structure termed actomyosin 
(also known as stress fibres) ${ }^{61}$. In the majority of animal cells, cell mechanics are dictated by a mesh of actomyosin known as the cortex, a mechanically rigid and highly plastic structure immediately below the cell membrane ${ }^{62}$. Within this actomyosin mesh, myosin is able to pull on actin fibres, which generates considerable tension, or prestress $^{61}$. This actomyosin-generated tension in the cell cortex is responsible for cell shape and integrity in a fashion that parallels architectural tensegrity structures. ${ }^{63}$ Moreover, this tension propagates through cell-cell and cell-ECM junctions and as such is fundamental to the architecture and function of living tissues ${ }^{64}$. Actomyosingenerated tension is typically increased in the intracellular stress fibres that act as an essential link between the cytoskeleton and focal adhesions, which connect cells to the ECM. This role explains why regions of the cell near focal adhesions are stiffer than the surrounding areas ${ }^{61}$. For all these reasons, when assessing cell mechanics by AFM indentation, the moduli derived will be highly dependent on the exact membrane zone indented ${ }^{65}$, a clear source of variability.

Furthermore, it is important to understand that cytoskeleton fibres are not the only cell component to have an effect on cell stiffness or shape. Interactions of cytoskeletal fibres with the intracellular and extracellular environment are also involved. For example, cellular activity can take advantage of cytoplasmic changes and osmotic forces. Early theories hypothesized that local cell membrane protrusions (also termed blebs) were initiated by severing of cytoskeletal fibres, which was thought to locally reduce the elastic modulus and thereby lead to an increased cell volume owing to osmotic effects. The consequent rise in hydrostatic pressure was suggested to force the membrane into a protrusion, which would eventually be stabilized by actin diffusing into it and then polymerizing ${ }^{66}$. In 2005 , however, a more likely mechanism was suggested: that local actomyosin contraction at the cortex compresses nearby cytoplasm, which increases local hydrostatic pressure and leads to the formation of blebs even when cell membrane protrusion is opposed by membrane tension and osmotic pressure $^{67}$.

Together, these complex phenomena indicate how an appreciation of the mechanical heterogeneity of cellular components can facilitate understanding of the mechanical properties of whole cells. It is useful to picture a cell as composed of a membrane encapsulating a very complex elastic network comprising the cytoskeleton and organelles within a fluid (cytosol), collectively termed the cytoplasm ${ }^{67}$. Unlike most engineered gels, the cytoplasm is continuously out of equilibrium owing to the active 
role of molecular motors such as myosin. These motors expend energy and the resulting fibre polymerization and network contraction enable intricate mechanical events to take place at the cellular cortex. Accordingly, the cortex is characterized as an active gel ${ }^{68}$. Overall, it is important to understand that living cells integrate a set of mechanical properties that are among the most unique and complex found in nature, and which can currently be explained only by resorting to several different theories (Box 2). This heterogeneity will undoubtedly need to be considered when trying to assess the bulk stiffness of single cells ${ }^{69}$.

Secondly, when addressing the mechanical properties of cells in adhesive scenarios, it is important to understand that, as a consequence of adhesion and spreading, cells might become extremely thin ${ }^{70}$. As such, AFM indentation depths have to be taken into consideration to avoid 'bottom effects' (in which measured stiffness values are too high owing to an influence of the surface beneath the cells rather than the mechanics of cells themselves) $)^{71}$. Several methods of correcting for bottom effects can be applied in multilayer cell mechanics ${ }^{72}$. This effect might partially explain why some reported mechanical properties of cell monolayers grown on tissue culture polystyrene (TCP) might not recapitulate in vivo ones. Simultaneously, the surface to which the cells adhere also affects cytoskeletal tension and consequent bulk mechanics, and these factors should be preferentially analyzed on surfaces that are mechanically as nativelike as possible. For example, the elastic modulus of thyroid cells is over twofold higher when cultured on TCP rather than on a softer, thyroid-like surface ${ }^{73}$. Nevertheless, even when the moduli mismatch of cells grown on a native-like surface is not as large as that of cells cultured on TCP, bottom effects might still have a considerable effect on measurements of relevant moduli, indicating the need for adequate correction ${ }^{74}$.

Cell spreading and surface stiffness are not the only sources of variability. In fact, when cells are constrained in a fixed area, the shape they assume can have a greater effect on their mechanics than the surface stiffness itself, which is especially important to consider when cells are cultured on surfaces with non-flat topographies (such as grooves or micropillars) ${ }^{75,76}$. This knowledge might also prove important in future initiatives to standardize the measurement of cell mechanics and thereby obtain more uniform, comparable results. The health status of cells can also give rise to large differences in stiffness (discussed in the 'Abnormal tissue states' section).

Altogether, the mechanical properties of cells reflect interesting biological events of relevance to tissue engineering. For example, with regard to cell 
differentiation, adult stem cells from different niches were shown to have distinct elastic moduli depending on their commitment: osteogenic stem cells were stiffer than adipogenic stem cells ${ }^{77,78}$. Similarly, the differentiation of embryonic stem cells (ESCs) is intimately connected to changes in stiffness ${ }^{79,80}$. Although the mechanical properties of cells themselves cannot yet be artificially engineered or directly manipulated, the

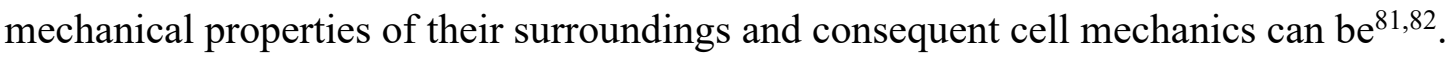
Nevertheless, understanding the mechanics of bulk tissues requires not only an overview of single-cell and ECM structural mechanics but also an understanding of how single-cell mechanics integrate to generate the mechanics of multicellular structures, and of how single-cell and multicellular mechanics combine with ECM mechanics to generate overall tissue mechanics.

\section{[H2] Cell-cell and cell-ECM interactions}

Many cell types are able to self-assemble into multicellular monolayers resembling the epithelial sheets formed during early development. Where cells contact each other, they form cell-cell adhesions through the binding and assembling of specific proteins, such as cadherins and catenins ${ }^{83}$. Interestingly, the resulting epithelial sheet still behaves actively in mechanical terms, just as single cells do, being able to sustain extreme strain under constant tension ${ }^{84}$. As the number of constituent cells increases, the active tension of the resulting monolayer also increases in a linear fashion ${ }^{85}$. In this scenario, where the predominant interactions are between cells rather than with the minimal ECM, stresses can propagate over long ranges ${ }^{86}$. In fact, monolayers of up to thousands of cells were shown to undergo stress relaxation very similarly to single cells, in that the cell-cell junctions serve as stable connections enabling these monolayers to behave in mechanical terms as single cells ruled by actomyosin dynamics ${ }^{87}$. Briefly, the application of sufficient stress leads to the rearrangement of intracellular actomyosin, which in turn promotes extension of the monolayer, thereby dissipating stress and resulting in a new mechanical steady state ${ }^{87}$. However, once a stiff ECM is present, stress no longer propagates across the monolayer in the same way ${ }^{86}$.

As cells begin to aggregate and organize into multilayered 3D structures, such as organs and tissues, the number of cell-cell interactions increases substantially ${ }^{88}$. Interesting research on the mechanics underlying early development has shown that the viscoelastic (stress relaxation) behaviour of cells still occurs in embryonic tissue and that the overall stiffness of this tissue is also close to that of single cells (below $1 \mathrm{kPa})^{89}$. 
Nevertheless, the elastic modulus of embryonic tissues shows considerable variation and is also responsible for driving morphogenesis ${ }^{89}$. At this stage, tissue responses are guided not only by quick-dissipating cellular stresses but also by supracellular, persistent ones ${ }^{90}$.

The initial phases of tissue formation occur in extremely dynamic, active and soft environments, where three essential entities govern mechanical outcomes: volumetric growth (mainly driven by cellular proliferation), active forces and the material properties of local tissues ${ }^{91}$. The precursors of cartilage, bone, and other stiff and soft tissues are all present within this soft structure, some of which must progressively stiffen by up to seven orders of magnitude to reach the $20 \mathrm{GPa}$ of cortical bone $^{92}$. This requirement leads to two important principles: first that, fundamentally, tissue development always proceeds in the direction of increasing stiffness. Soft environments are always present before stiffer ones arise - even after a bone fracture, the regeneration of bone is preceded by the accumulation of considerably softer materials: haematoma, granulation tissue and fracture callus (in order of increasing stiffness), within which ECM fibres accumulate and eventually mineralize to form stiff bone ${ }^{93,94}$. In order to understand how early embryonic structures stiffen and eventually develop the mechanical characteristics of mature tissues, we must further consider the interplay of ECM and cellular mechanics.

The early embryonic ECM acts mostly as a basement membrane for embryonic epithelia. Nevertheless, the mechanical effects of cell-ECM interactions can first be observed here. Epithelial cells, as part of their normal activity, secrete and deposit ECM fibrils, which form the basement membrane to which the cells adhere, thereby gradually increasing its stiffness ${ }^{95}$. The stiffness of this early extracellular structure then begins to overtake that of the attached cells, increasing from $20 \mathrm{kPa}$ at early embryonic stages up to $800 \mathrm{kPa}$ at later time points. Additionally, the ECM fibrils have a preferential orientation that leads to heterogeneous directional stiffness ${ }^{95}$, which represents the earliest appearance of ECM-related tissue anisotropy. In the embryonic stages of nematode development, the apical ECM was shown to be essential for cell anchoring and transmission of actin-derived stresses, through the formation of an actin-ECM composite with distinct mechanical properties ${ }^{96}$. It is this very early ECM configuration that causes the shift in mechanics from single cell-like to tissue-like, although the embryonic tissue still goes through considerable further dynamic changes related to cell migration and morphogenesis ${ }^{97}$. 
As the development of these embryonic structures continues, so does the deposition and accumulation of ECM, thereby generating ever more complex structures. Eventually, this process leads to the formation of stiffer tissues. The mechanics of some of these stiffer tissues are mostly dependent on the ECM, whereas the stiffness of softer, highly cellular tissues is closer to that of their constituent cells. Cardiomyocytes have elastic moduli close to those reported for cardiac tissue ${ }^{98}$ because the mechanics of muscle tissue are principally dependent on those of its contractile, actomyosin-rich cells $^{99}$. By contrast, both mesenchymal stem cells (MSCs, also known as bone marrow stromal cells) and the osteoblasts they differentiate into during osteogenesis are quite soft in comparison to bone ${ }^{78,100}$ because bone mechanics are mostly governed by the abundant, highly mineralized ECM. Naturally, in highly cellular tissues at late stages of development, the heterogeneity and mechanics of the constituent cell types play an important part in the final stiffness of the tissue ${ }^{101}$. Behind this heterogeneity are differences in cell types and their respective structures, spanning from the cell membrane ${ }^{102}$ to the previously discussed intricacies of intracellular architecture.

Benchmarking of tissue engineering approaches against knowledge obtained from developmental biology has already proved important in the recapitulation of adequate stimuli prompting the in vitro generation of desired cell phenotypes ${ }^{103}$. Even though much remains to be learned within this field, understanding of how the mechanics of different biological components are integrated into a tissue is already possible on a basic level, and is expected to facilitate similar analyses of fully developed biological structures.

\section{[H1] The stiffness range of living tissues}

Not surprisingly, a system as complex as a human organism comprises tissues that span a remarkable spectrum of stiffness; elastic moduli range from the $11 \mathrm{~Pa}$ of intestinal mucus $^{104}$ to the $20 \mathrm{GPa}$ of cortical bone ${ }^{92}$. Between these extremes, almost all orders of magnitude are represented by a distinct tissue (Fig. 2).

Neural tissues are amongst the softest of the human body ${ }^{105}$, which should be expected considering their anatomical protection and how easily they can be damaged. These are followed by most abdominal organs (such as the pancreas, spleen and liver) and muscles, and finally by supportive structures such as cartilage, tendons, ligaments and eventually bone. From the analysis of the compiled information (Table 4, Supplementary Table S1), some important points are worth discussing further. 


\section{[H2] Dimension scale and direction}

Differences between tissue mechanics measured at nanoscale, microscale or macroscale dimensions are extremely relevant to tissue engineering and therefore dimension should always be considered (Table 4, Supplementary Table S1). Such differences of scale are mostly a consequence of the heterogeneity of biological tissues, as other authors have already reported ${ }^{106}$. In general terms, if a tissue is deformed in a tensile manner or the whole tissue is compressed, the behaviour of the bulk material contributes to the overall measured mechanical moduli. By contrast, if a tissue is indented, only the region where the indentation takes place (and eventually its nearby surroundings) will contribute to the measured moduli. The smaller the indenting tool (for example, microscale versus nanoscale), the less likely it is that the measured moduli will be representative of the whole tissue ${ }^{106}$. For example, the response to compression of a whole bone sample integrates both trabecular and cortical bone mechanics, whereas microindentation of the same sample is likely to reflect deformation of only one of these two types of bone ${ }^{107}$ and nanoindentation will target only a single cell (such as an osteoblast) or ECM component (such as a collagen fibre) ${ }^{108}$.

Similarly, microindentation studies of spinal cord reported values within the 0.5-1.5 $\mathrm{kPa}$ range ${ }^{109}$, whereas tensile deformation studies reported values three orders of magnitude higher $(1.23 \mathrm{MPa})^{110}$. However, microindentation involves not only a difference of scale when compared with tensile deformation, but also a difference in the direction of the applied force; microindentation is usually transverse to the tissue, whereas tensile deformation is mostly longitudinal. In fact, other corroborative evidence is provided in reports showing that dermis macroindentation results in elastic moduli of $\sim 35 \mathrm{kPa}^{111}$ whereas tensile deformation results in elastic moduli in the $50-150 \mathrm{kPa}$ range $^{112}$. Even when, as in this case, analyses were conducted at the same scale (which might be expected to lead to a fairly small discrepancy), substantial differences can result from altered directionality. These factors explain why certain techniques are not appropriate for direct comparison. Even if the same type of modulus is derived, the dimension at which it is measured as well as its direction must always be considered.

The mechanics of engineered tissues at all dimensions are fundamental for their function: the bulk mechanics are important to ensure in vivo stability whereas microscale and/or nanoscale properties are essential for regulating cellular behaviour ${ }^{113}$. 


\section{[H2] Tissue anisotropy or composite material}

Composite materials are made of distinct components, each with different properties, that when combined form a material with properties that are different from those of the individual constituents. These materials are used in high-end applications owing to their optimal performance and as such, natural evolution might have followed a similar path $^{114}$. In fact, many biological tissues easily fit within the above definition of composite materials $^{115}$. Some even seem to be composite materials made of other composites, tendon being an obvious example ${ }^{116}$. A tendon is a hierarchical structure made of various types of collagen fibres bundled together in subfascicles, which in turn are bundled into fascicles of increasing hierarchy to form the tendon itself. This organization resembles that of synthetic composite materials consisting of fibres with specific unidirectional mechanical properties bundled together by a resin, which results in a highly anisotropic material. Similarly, tendons are capable of sustaining a high level of stress through tensile deformation of the collagen fibres and fascicles. The resulting tissue anisotropy is the reason why some mechanical relationships (such as equation 3 ) do not hold true and should not be employed in the analysis of biological tissue mechanics, and also explains the differences in elastic moduli derived by mechanical tests employing different directions of deformation.

Parallels could also be drawn between laminated composite materials and organs such as the skin, which is composed of three layers of distinct but interacting tissue (epidermis, dermis and hypodermis). The skin has bulk elastic moduli of up to several hundred $\mathrm{kPa}^{117}$ whereas the fibre-reinforced dermis ${ }^{118}$ has elastic moduli of around 35 $150 \mathrm{kPa}$ and the hypodermis has elastic moduli of around $2 \mathrm{kPa}$, similar to adipose tissue ${ }^{111,112,119,120}$. The lens of the eye comprises a stiff capsule with elastic moduli of 2$3 \mathrm{MPa}$ and a very soft core $(0.8-11.8 \mathrm{kPa})^{121-124}$. In the lung, the pleura are also considerably stiffer than the parenchyma ${ }^{125}$ (Supplementary Table S1). In such tissues, the mechanics of individual components might be more relevant for their engineering than the bulk tissue properties. Finally, some organs also present variable mechanics along their length; for example, the elastic moduli of gut tissue range from $789 \mathrm{kPa}$ at the ileum to $323 \mathrm{kPa}$ at the descending colon ${ }^{126}$.

\section{[H2] Tissue condition}

Tissue condition can also have important mechanical consequences. Bone mechanical properties can differ depending on collection site, processing method and storage ${ }^{127}$ as 
well as host-related factors such as age and health status ${ }^{128}$. Several reports have also considered the mechanical properties of decellularized tissues, which not only lack the cellular component but are frequently stiffer than native tissue as a result of the treatments needed to remove cells. This increased tissue stiffness has been reported for decellularized lung ${ }^{129}$, pancreas ${ }^{130}$ and fat ${ }^{131}$. Furthermore, even with cellular tissues, increased preservation duration can also lead to stiffening, as shown with liver ${ }^{132}$.

\section{[H2] The applied deformation}

Native-like deformations are generally the most useful to derive mechanical properties relevant to tissue engineering. For example, the mechanics of bone and cartilage might seem fairly straightforward to analyze. However, bone can be considered a composite material consisting of mineral, organic and water phases. A compressive test under static load would be useful to characterize the contribution of the mineral component (which mainly has an elastic response) to bone mechanics, but only dynamic analysis would be able to integrate the viscous contribution of the collagen-rich organic phase, which confers damping and shock-absorption properties on bone. Similarly, testing of dry bone will not assess the contribution of hydration ${ }^{133}$. Articular cartilage, moreover, must support the interfaces between bones at the joints and allow the relative movement of limbs. Therefore, cartilage is natively subjected to repetitive, cyclic stress involving compressive as well as shear forces, which is why engineering of this tissue presents such a therapeutic challenge ${ }^{134}$. As such, emphasis should be given to DMA and tests such as shear rheology. In fact, cartilage can have higher moduli under dynamic testing than under static deformation ${ }^{135-137}$ as a consequence of the previously discussed electrostatic and solid-fluid interactions. Furthermore, the long-term responses of complete tissues to applied stress or deformation (such as creep and strain relaxation) are thought to be crucial for their physiological behaviour. As an example, blood vessels dilate in response to increased blood flow ${ }^{138}$. Nevertheless, these responses are frequently not considered in studies of tissue mechanics.

\section{[H2] Nonlinear behaviour}

Several biological tissues do not have a linear stress-strain relationship, and this nonlinearity can hinder comparisons of different studies on the mechanics of living tissues. Examples of nonlinearity show up in early epithelial monolayers ${ }^{86,87}$ and can also be seen in adipose tissue, skin and even in tendons, which all deform easily at low 
levels of strain but become much stiffer as strain increases ${ }^{38,139}$. In tendons, as the tissue stretches, collagen fibrils and cells become more aligned, resulting in an extremely stiff structure that can easily reach elastic moduli of $100-200 \mathrm{MPa}^{140}$. This particular mechanical response of tendons is also responsible for their negative Poisson's ratio ${ }^{34}$. Therefore, when studying tissues with nonlinear stress-strain relationships, emphasis should be given to strain levels and low strain deformations should not be compared to high strain ones.

\section{[H2] Gaps in the literature}

Many examples exist of tissues that have been far less thoroughly explored with regard to their mechanical properties. Peripheral nerves, ligaments, gut tissue and spleen have been analyzed in depth at bulk, macroscale dimensions, but lack further study at nanoscale or microscale levels. In other tissues, little to no exploration of mechanics has been done. For example, the mechanical properties of the thymus have only been reported for decellularized tissue ${ }^{131}$. Other tissues, such as skin, require further exploration at smaller scales to clarify some discrepancies; the mechanical stiffness of epidermis is higher than that of dermis in some ${ }^{141}$ but not all ${ }^{142}$ nanoindentation studies. Further analysis is necessary to fully understand and to engineer the multilayered mechanics of skin and skin-like constructs.

\section{[H1] Abnormal tissue states}

Scientists have identified several different causes of altered tissue stiffness, including cancer, advanced age, diabetes mellitus, cardiovascular disease and fibrosis ${ }^{143}$. Nevertheless, some changes in bulk mechanics are not truly caused by changes in the tissues themselves but rather are attributable to changes in blood pressure and their circulatory consequences. For example, spleen stiffness can increase from $15-20 \mathrm{kPa}$ in healthy individuals ${ }^{144-147}$ to $50 \mathrm{kPa}$ in patients with liver fibrosis ${ }^{148}$ — an abnormal spleen state that is not a consequence of having abnormal spleen tissue. In the next sections, we discuss the main causes of abnormal tissue mechanics: fibrosis and cancer (Fig. 3). Of note, most ECM changes in individuals with cancer are fibrotic responses to the neoplastic event ${ }^{149}$.

\section{[H2] Fibrosis}


Fibrosis can be briefly described as the aberrant deposition and accumulation of connective-tissue-like ECM in a tissue or organ resulting from an imbalance between its production and degradation. This imbalance leads to the formation of a disorganized and excessively crosslinked fibrous network, along with the release of inflammatory signals, myofibroblast differentiation and other cellular and/or molecular events ${ }^{150,151}$ resulting in a tissue with increased overall stiffness. Although these adverse effects of fibrosis and/or scarring can be disregarded in small wounds, large cutaneous scars and widespread fibrosis in tissues or organs such as the lung ${ }^{152}$, kidney $^{153}$ and liver ${ }^{154}$ are serious life-threatening conditions. Interestingly, increased liver stiffness is itself a major diagnostic criterion for liver disease ${ }^{155}$; a fibrotic liver is stiffer than a healthy one at both macroscopic ${ }^{156,157}$ and microscopic levels ${ }^{158}$.

\section{[H2] Cancer}

Unhealthy cells, including cancer cells, frequently have altered mechanical properties, although the direction of these alterations shows no consistent trend. Some authors report that cancerous cells are stiffer than their healthy counterparts ${ }^{159,160}$, whereas others show the opposite ${ }^{5,161}$. Clearly, each type of tissue and disease can lead to distinct cell mechanical outcomes ${ }^{162,163}$. In fact, many of the signaling pathways that are frequently altered in cancer cells converge on changes in the expression of cytoskeleton-associated proteins, namely those responsible for actin fibre polymerization and myosin contraction ${ }^{164,165}$. These processes are fundamental for the mechanical properties of cells and can even have a direct effect on the ECM mechanics of tumours. Thus, since cancer cell signaling is highly heterogeneous and varies not only with the type of cancer but also within the same disease type, it is natural that this heterogeneity might equally transpose to the resulting cancer cell stiffness.

Cancer has been characterized as "a wound that does not heal"166. As such, much of the characteristics of a non-healing, fibrotic wound are shared by neoplastic lesions. In both injury and neoplasia, abnormal cell proliferation leads to a desmoplastic response (that is, dense overgrowth of basement-membrane-like connective tissue with low cellularity and either a translucent, cartilage-like appearance or a hardened texture with disorganized blood vessel infiltration). ECM deposition and tissue stiffening similarly occur in the tumour microenvironment ${ }^{149}$, where these processes are further amplified by the ability of cancer cells to drive stromal cells towards a profibrotic phenotype ${ }^{167}$. In cancer, moreover, the abnormal cell proliferation also generates 
increased solid stress, caused not by a change in the stiffness of the tissue itself but instead by the increased pressure resulting from tumour growth in a constrained physical volume (mass effects), which compresses nearby healthy tissue ${ }^{149}$. Together with the increased solid stress, the previously discussed increase in cancer cell tension derived from actin and myosin-related signaling might also increase the stiffness of nearby ECM via tensing or realignment of ECM fibres ${ }^{168}$. The combination of increased cell stiffness and solid stress can drastically increase the stiffness of some malignant lesions: the elastic moduli of healthy thyroid tissue $(9.0-11.4 \mathrm{kPa})$ can increase by a full order of magnitude to $44-110 \mathrm{kPa}$ in patients with papillary adenocarcinoma ${ }^{169}$.

\section{[H2] Chronic diseases}

Last but not least, the mechanical properties of tissues might also be affected in other potentially life-threatening chronic diseases unrelated to fibrotic responses or neoplastic alterations. For example, amyloid deposition diseases such as Alzheimer disease ${ }^{170}$ and cardiac muscle hypertrophy both increase tissue stiffness ${ }^{171}$, whereas osteoporosis reduces bone strength and stiffness ${ }^{172}$.

Altogether, we believe that pathological changes in tissue stiffness can always be traced to altered amounts or functions of its two fundamental constituents: cells (number and/or phenotype) and ECM (deposition and/or degradation). Knowledge of abnormal tissue states and the mechanical changes that take place in disease are important not only for diagnostic purposes but also for tissue engineering and recapitulation of such diseases in in vitro models. These approaches are expected to generate novel therapeutic targets that enable restoration of healthy tissue mechanics and mechanotransduction responses ${ }^{150}$.

\section{[H1] Engineering stiffness into tissues}

Once the mechanics of a complete native tissue are understood, the question that remains is how can one engineer such mechanics when attempting to construct a lifelike tissue? This question led tissue engineers to search for novel materials, natural and synthetic, alone or blended together and processed through physically, chemically and biochemically distinct approaches in the attempt to recapitulate the properties of living tissues. Several main approaches to engineering the mechanical properties of living tissues and ways to trigger desired mechanotransduction responses by cells can be identified in the literature (Fig. 4). 
The stiffness of structures (in its simplest form, their elastic or shear moduli) is the oldest target within the field. If in the beginning the mechanical properties of a bulk material were only seen as a requirement for scaffold integration and integrity ${ }^{2}$, emerging discoveries and the rise of mechanobiology ${ }^{113}$ have placed mechanical properties at the same level as long-known biochemical cues. Changing the elastic moduli of the cellular environment, either approaching or moving away from those of native tissues, can lead to tremendous differences in cellular responses from simple adhesion ${ }^{173,174}$ and morphology ${ }^{175-177}$ to the more complex differentiation ${ }^{178-180}$. In fact, this variation can be of such magnitude that high-throughput technologies are now being applied to derive the best-fit conditions in terms of surface stiffness for distinct cell types ${ }^{174,181}$, and approaches to do the same in 3D environments are both needed and expected.

Nevertheless, the scientific community has started to shift its attention to more complex stiffness scenarios involving dynamic and active tissue mechanics (reviewed elsewhere in the epithelial context ${ }^{182}$ ). Two seminal works brought to light the possibility of achieving and tuning life-like, time-changing forces in $3 \mathrm{D}$ environments by exploring the properties of biomimetic material that have profound effects on cellular behaviour, possibly greater than the influence of static stiffness ${ }^{81,94}$. Stress stiffening and stress relaxation represent the capability of specific materials to stiffen or relax with stress state or time, respectively. Initially reported on two-dimensional (2D) surfaces ${ }^{183,184}$, these properties were soon translated to 3D environments and have proved to be very important.

\section{[H2] Stress stiffening}

Stress stiffening is a natural property observed in many biological structures, such as gels of the cytoskeletal proteins actin and vimentin.Other ECM molecules, such as collagen and fibrin, also exhibit substantial increases in stiffness beyond a critical stress value $^{185,186}$. This behaviour is fundamental for the proper function of many biological structures and its translation to synthetic materials eluded scientists for quite some time. Once engineering of stress stiffening became possible, controlled changes in the onset of stiffening alone (within the same final modulus) were shown to be single-handedly capable of redirecting the commitment of MSCs from adipogenic to osteogenic lineages ${ }^{81}$. A report published in 2019 showed that this kind of stress stiffening could be 
tuned to encompass a 50-fold increase, similar to the forces exerted by myosin molecular motors: a remarkably life-like scenario ${ }^{187}$.

\section{[H2] Stress relaxation}

Stress relaxation represents the capability of a material to relax at a specific time point after the induction of stress, which dissipates energy through a viscoelastic response as opposed to a purely elastic one (for example slippage versus stretching of chemical bonds in a covalently crosslinked hydrogel ${ }^{183}$. Viscoelasticity is also present in many biological tissues consisting of a fibrous network (such as collagen) within a nonfibrillary $\mathrm{ECM}^{188}$. Such viscoelastic behaviour is fundamental for the normal functioning of tissues that are naturally subjected to dynamic loads, including the lung, cartilage and tendons. However, even stiff tissues such as bone exhibit appreciable stress relaxation during active regeneration ${ }^{94}$. Moreover, stress relaxation of engineered tissues is, like stress stiffening, capable of affecting stem cell differentiation ${ }^{94}$. Remarkably, in non-adhesive environments, stress relaxation alone was enough to completely shift the behaviour of chondrocytes from round and static to life-like cartilage-forming entities ${ }^{189}$. This phenotype change was due to the ability of the engineered material to relax faster than a sample that lacked stress relaxation but had similar initial stiffness, which enabled the cells to become less confined, expand, proliferate, and behave as they would in their native environment.

However, all these studies involved hydrogel structures with low moduli of a few $\mathrm{kPa}$. Despite being far from the stiffness of cartilage or bone, these hydrogel environments strongly promoted osteogenic and chrondrogenic commitment ${ }^{81,189}$. As previously mentioned, the natural evolution of tissues during development progresses from soft to stiff environments (for instance, bone and cartilage both develop from soft precursor structures), and so it is only logical that soft environments would promote tissue development. An engineered structure as soft as adipose tissue, which never matures into a stiffer tissue, can never mechanically replace missing mature cartilage or bone. Nonetheless, the evidence obtained in both living tissues and engineered structures clearly indicates that a certain degree of dynamicity resulting from either stress relaxation or stress stiffening (both of which approximate the natural stimuli that cells receive) is of primal importance for recapitulating appropriate cellular behaviour.

\section{[H2] Mechanical stimulation}


Not all materials are capable of dynamic features and specific applications might require the use of static structures. As such, tissue engineers have been attempting to approximate in vitro the dynamic fluctuations in force and shape that happen in vivo by actively stimulating cell-material constructs with controlled mechanical deformations. This approach has in fact been exploited for quite some time ${ }^{190}$ but is increasingly explored in tissue engineering for the maturation of constructs. Most of the time, the stimulus is an attempt to recapitulate stresses that the native tissue endure in vivo, such as compression and shear forces in cartilage differentiation ${ }^{191}$ or tensile deformations in skin and hair regeneration ${ }^{192}$. In other circumstances, not-so-native forces can also prove effective, such as stretching in cartilage formation ${ }^{193}$ or even nanovibrations of MSCs in osteogenesis ${ }^{194}$.

\section{[H2] Time-dependent changes}

One further option to achieve time-dependent changes is to use cells as the actuators. In fact, this quite lively field of study represents a new paradigm in modern tissue engineering. Traditional tissue engineering approaches have aimed to direct cell behaviour by actively stimulating specific cellular receptors and pathways using bioactive molecules, ligands and scaffolds. Although these methods have shown promising outcomes, we now appreciate that providing cells with a material environment that they can remodel, both biochemically and mechanically, might be equally or even more important. Such materials could be defined as biolabile rather than bioactive, meaning that they are prone to change and remodeling. Similarly, such environments enable cells to bind to, degrade, or plastically open up gaps to move through it ${ }^{195}$, to physically contract and mechanically change its shape ${ }^{196}$, or to expand, remodel and deposit their own proteins on it ${ }^{197}$. The results of these 2018-2019 studies ${ }^{195-197}$ show that tissue engineering might benefit not only from highly specific cell stimulation cues but also from the cells "mastering their own fates through the matrix" $" 198$, in vitro. Eventually, both types of stimuli might be employed, as happens in vivo where local entities remodel and regenerate tissues but also respond to systemic cues.

In fact, in vivo degradability and remodeling further highlight time-dependent changes as an important dimension of engineered tissue mechanics. The development of materials that degrade in close conjunction with the formation of new tissue is the holy grail of tissue engineering - the desired outcome being total regeneration of native 
tissue and the complete removal of synthetic material or the appropriate remodeling of a natural scaffold. This degradability implies that the mechanical properties of the engineered tissue substitute will vary over time. Although it is outside the scope of this Review to discuss the complex concept of degradability after implantation, it is important to consider that different degradation mechanisms of the tissue substitute could lead to different changes in its mechanical properties through time. Degradation of polymeric substitutes, for example, might occur on the surface and/or in the bulk, with or without a change in molecular weight ${ }^{199}$, which raises the prospect of timevarying changes in their mechanical properties after implantation ${ }^{200}$ combined with the previously discussed matrix deposition and remodeling by cells both from the construct itself and resident in its vicinity. These changes, even if desirable and necessary for true construct integration, make post-implantation outcomes extremely complex. As such, advanced translational strategies might benefit from applying predictive methods such as machine learning ${ }^{201}$ to understand and improve post-implantation outcomes.

\section{[H2] Interface tissues}

Additionally, the mechanical changes natively occurring in biological tissues often also have a spatial element, which can be challenging to recapitulate. However, some tissue structures naturally bridge two distinct environments with different mechanics (typically one soft and one stiff material). Such tissues are often found in vivo in locations where transitional tissues are formed, such as in cartilage-to-bone, meniscus-to-bone, tendon or ligament-to-bone and muscle-to-tendon interfaces ${ }^{202}$.

Attempts to engineer similar structures have mainly focused on combining two mechanically distinct compartments (which might also have other distinct characteristics) into a single structure mimicking either a bone and tendon interface ${ }^{203,204}$ or a cartilage and bone interface ${ }^{205}$, while hoping that the interface region is stable enough (and large enough) to house intermediate cell phenotypes and behaviours. However, interface tissues in vivo typically demonstrate a gradient in which changes are gradual rather than binary. Similar gradients have been produced for osteochondral tissue engineering ${ }^{206}$, an interesting yet challenging approach to the creation of life-like interfaces. Nevertheless, materials with 3D gradients in mechanical characteristics are still scarcely reported in the literature, and it will be interesting to see what the future holds with regard to this approach to interface tissue fabrication, as scientists begin to develop the toolbox for soft-to-hard tissue bioengineering ${ }^{207}$. 


\section{[H1] Future perspectives}

Scientists are beginning to develop and employ advanced biofabrication technologies to mimic the natural properties of biological tissues across different scales. Examples can be seen in the fields of additive manufacturing, where the precise control and recapitulation of complex biological shapes ${ }^{208}$ is being combined with advanced bioinks for 3D printing ${ }^{209}$. Meanwhile, metamaterial research is also delivering very exotic shapes with complex mechanical functionality to distinct structures ${ }^{210,211}$ and it will be exciting to see how these properties might be combined with biological systems. Simultaneously, a clear trend is evident towards the engineering of materials with timevarying mechanics, which have been achieved either through material-intrinsic stress relaxation and/or stress stiffening or through external mechanical stimulation. Thus, modern approaches to mechanical tissue engineering, which focus on maximizing cell stimulation, seem to be drifting away from the classic paradigm of biomechanical tissue replacement.

Although these are very interesting approaches, they come with one overall caveat: extremely soft environments (up to few $\mathrm{kPa}$ ) have been shown to promote the best cellular responses even when used for generation of a stiff tissue. How then can these soft engineered structures reach the elastic moduli of their living counterparts? Can we integrate time-dependent changes in mechanics into stiffer structures and still obtain the desired cellular responses? Will cellular proliferation, ECM deposition and overall tissue maturation lead to appropriate construct stiffening or can we push the capacity for stress-stiffening of currently available materials to even higher orders of magnitude?The answers to these essential questions will inform how to efficiently combine the biological advantages of soft environments with the mechanical resilience of stiff structures. Furthermore, an important need remains for further manipulating very uniform materials to approach natively non-uniform structures, such as the interfacial gradients, anisotropic environments and overall multiscale biological complexity discussed in this Review. In this regard, interesting advances have been reported in nanocomposite hydrogels ${ }^{212}$ and combinations of hydrogel printing with electrospinning ${ }^{213}$ that enable the introduction of shape and directionality into engineered constructs. Finally, the effects of post-implantation events, particularly remodeling and degradability, on construct mechanics represents an additional level of 
complexity that is as yet far from being decoded and properly integrated within tissue engineering strategies.

\section{[H1] Conclusions}

We have seen that biological tissues have very distinctive mechanics due to their structural complexity and heterogeneity, which only increase with evaluations of the properties of their individual constituents (both ECM and cells). Regarding bulk tissue mechanics, a substantial amount of literature is derived from different animal models and distinct techniques. However, high levels of disparity persist when some values are derived and wrongful comparisons are made by not considering the dimension and/or type of deformation studied (in terms of its magnitude, directionality and dynamicity). Furthermore, some bulk tissues have only been analyzed at a single dimension (macroscale, microscale or nanoscale). As a consequence, these disparities raise questions that demand further research.

At microscale and nanoscale dimensions, the mechanics of several ECM structures remain unexplored, despite their well-known biochemical roles. Future research into these structures might be important to improve our understanding of how they contribute to bulk tissue mechanics and also for improving homogenization; that is, the prediction of bulk material properties informed by knowledge of their microscale components' mechanical behaviour, as discussed in the 'Spatial scale' section. Additionally, cellular mechanics reveal themselves to be extremely complex, even in the cell types for which a good picture is already established. At this level, two main challenges seem to remain: first, the unification of tensegrity and soft glassy rheology models (Box 2), both of which might be linked by the pre-stress role of the cytoskeleton, and second, translation of the knowledge derived from cells in monolayer cultures to those within 3D environments, where further complexity is likely to arise. Closing these and other gaps in knowledge will illuminate the interplay of force and shape in biological tissues and will underlie the roadmap for engineering life-like structures in health and disease states.

It seems clear that there will never be a true standard for the mechanical analysis of biological tissue and that variability in the results of such analyses will always be high. Nevertheless, we believe that by properly integrating the results derived from different analysis methods towards material-translatable conclusions, the mechanical intricacies of living tissues can be well understood. Similarly, the tools to recapitulate 
each individual tissue might soon be at our disposal. Understanding how to exploit synergies between soft and stiff materials to maximize cell stimulation while also approaching the mechanics of the mature biological tissue could be the final frontier for engineering truly life-like tissues.

\section{Acknowledgements}

The authors would like to acknowledge financial support from the European Research Council, grant agreement ERC-2012-ADG 20120216-321266 (project ComplexiTE). C.F.G. acknowledges scholarship grant no. PD/BD/135253/2017 from Fundação para a Ciência e Tecnologia (FCT). The authors also thank the peer-reviewers for the constructive comments and suggestions that helped to shape this manuscript.

\section{Author contributions}

C.F.G. and L.G. contributed to all aspects of the article. R.L.R. and A.P.M. contributed substantially to discussions of the article content and review or editing of the manuscript before submission; A.P.M. additionally contributed to writing the manuscript.

\section{Competing interests}

The authors declare no competing interests.

\section{Publisher's note}

Springer Nature remains neutral with regard to jurisdictional claims in published maps and institutional affiliations.

\section{Supplementary information}

Supplementary information is available for this paper at https://doi.org/10.1038/s415XX-XXX-XXXX-X

\section{ALL LINKS ARE ACTIVE IN THE ONLINE PDF}


Table 1 Commonly used techniques for the mechanical characterization of living tissues.

\begin{tabular}{|c|c|c|c|c|c|c|}
\hline Technique & Concept & Moduli & Sample & Dimension & $\begin{array}{l}\text { Standard test } \\
\text { methods* }\end{array}$ & Refs. \\
\hline $\begin{array}{l}\text { Tensile } \\
\text { deformation }\end{array}$ & $\begin{array}{l}\text { Classic stress-strain analysis. } \\
\text { Uniaxial stress is applied to stretch } \\
\text { the material and a relationship is } \\
\text { established with the resulting strain }\end{array}$ & $E$ (elastic) & $\begin{array}{l}\text { Mostly ex } \\
\text { vivo tissue }\end{array}$ & Macroscale & $\begin{array}{l}\text { D412, D638, } \\
\text { D882, D1623, } \\
\text { D1708, D3039, } \\
\text { D3039M }\end{array}$ & 214 \\
\hline $\begin{array}{l}\text { Compressive } \\
\text { deformation }\end{array}$ & $\begin{array}{l}\text { Classic stress-strain analysis. } \\
\text { Uniaxial stress is applied to } \\
\text { compress the material and a } \\
\text { relationship is established with the } \\
\text { resulting strain; the compressor is as } \\
\text { the same size or larger than the } \\
\text { sample }\end{array}$ & $E$ (elastic) & $\begin{array}{l}\text { Ex vivo } \\
\text { tissue }\end{array}$ & Macroscale & D695, D1621 & 215 \\
\hline $\begin{array}{l}\text { Dynamic } \\
\text { mechanical } \\
\text { analysis }\end{array}$ & $\begin{array}{l}\text { Cycles of tensile and compressive } \\
\text { deformations }\end{array}$ & $\begin{array}{l}E^{\prime}, E^{\prime \prime} \\
\text { (viscoelastic) }\end{array}$ & $\begin{array}{l}\text { Ex vivo } \\
\text { tissue }\end{array}$ & Macroscale & D5024,D5026 & 216 \\
\hline $\begin{array}{l}\text { Shear } \\
\text { rheometry }\end{array}$ & $\begin{array}{l}\text { Application of small-amplitude } \\
\text { oscillatory shear stress and } \\
\text { quantification of the resulting strain }\end{array}$ & $\begin{array}{l}G^{\prime}, G^{\prime \prime} \text { (shear, } \\
\text { viscoelastic) }\end{array}$ & $\begin{array}{l}\text { Ex vivo } \\
\text { tissue }\end{array}$ & Macroscale & D5279 & 217,218 \\
\hline $\begin{array}{l}\text { Pipette or } \\
\text { micropipette } \\
\text { aspiration }\end{array}$ & $\begin{array}{l}\text { Establishment of the relationship } \\
\text { between the pressure of aspiration } \\
\text { and aspirated volume of the sample }\end{array}$ & $E$ (elastic) & $\begin{array}{l}\text { Ex vivo } \\
\text { tissue }\end{array}$ & $\begin{array}{l}\text { (Microscale), } \\
\text { macroscale }\end{array}$ & NA & 219,220 \\
\hline Indentation & $\begin{array}{l}\text { Indentation of the tissue with a probe } \\
\text { of defined geometry, and calculation } \\
\text { of the relationship between } \\
\text { indentation depth and probe load } \\
\text { (the probe must be smaller than the } \\
\text { sample) }\end{array}$ & $E$ (elastic) & $\begin{array}{l}\text { Mostly ex } \\
\text { vivo tissue }\end{array}$ & $\begin{array}{l}\text { Nanoscale to } \\
\text { macroscale }\end{array}$ & E2546-15 & 106,221 \\
\hline $\begin{array}{l}\text { Atomic force } \\
\text { microscopy }\end{array}$ & $\begin{array}{l}\text { Atomic-level indentation } \\
\text { (nanoindentation) or shear rheology } \\
\text { (atomic force microscopy-based } \\
\text { rheology) }\end{array}$ & $\begin{array}{l}E \\
\text { (indentation), } \\
G^{\prime}, G^{\prime \prime} \text { (shear) }\end{array}$ & $\begin{array}{l}\text { Dry or wet ex } \\
\text { vivo tissue }\end{array}$ & $\begin{array}{l}\text { Microscale, } \\
\text { nanoscale }\end{array}$ & NA & $5,142,222$ \\
\hline $\begin{array}{l}\text { Magnetic } \\
\text { resonance } \\
\text { elastography }\end{array}$ & $\begin{array}{l}\text { Magnetic resonance visualization of } \\
\text { tissue deformation resulting from the } \\
\text { introduction of shear waves into the } \\
\text { tissue derived from external } \\
\text { vibrations }\end{array}$ & $\begin{array}{l}G^{\prime}, G^{\prime \prime}(\text { shear, } \\
\text { viscoelastic) }\end{array}$ & In vivo tissue & $\begin{array}{l}\text { Macroscale } \\
\text { (millimetric) }\end{array}$ & NA & 223,224 \\
\hline $\begin{array}{l}\text { Ultrasonic } \\
\text { shear wave } \\
\text { elastography }\end{array}$ & $\begin{array}{l}\text { Ultrasonic pulses produce shear } \\
\text { waves through the tissue; the } \\
\text { velocity of these waves is measured } \\
\text { and used to derive the tissue's } \\
\text { Young's modulus }\end{array}$ & $E$ (elastic) & In vivo tissue & $\begin{array}{l}\text { Macroscale } \\
\text { (millimetric) }\end{array}$ & NA & 225 \\
\hline
\end{tabular}

*Additional test methods are suggested by American Society for Testing and Materials (ASTM)

F2150-13 where applicable; sample preparation and conditioning guidelines are provided by

ASTM F1634 and F163. 
Table 2 Mechanical moduli of extracellular matrix components.

\begin{tabular}{|l|l|l|l|}
\hline Component & Technique & E values & Refs. \\
\hline Collagen molecule & X-ray diffraction & $3-9 \mathrm{GPa}$ & 33 \\
\hline Collagen fibril & $\begin{array}{l}\text { AFM indentation or tensile } \\
\text { deformation }\end{array}$ & $\begin{array}{l}2-7 \mathrm{GPa} \text { (tensile), 5.0-11.5 GPa } \\
\text { (indentation) }\end{array}$ & 34 \\
\hline Collagen fibre & Micro-bending & $100-360 \mathrm{MPa}$ & 226 \\
\hline Fibronectin fibre & $\begin{array}{l}\text { Microelectromechanical } \\
\text { systems tensile deformation }\end{array}$ & Up to $3.5 \mathrm{MPa}$ (strain-dependent) & 50 \\
\hline Fibrin fibre & $\begin{array}{l}\text { AFM tensile deformation or } \\
\text { micro-bending }\end{array}$ & $1-28 \mathrm{MPa}$ & 227,228 \\
\hline Elastin fibre & \begin{tabular}{l} 
Tensile deformation \\
\hline
\end{tabular} & $1.1-1.2 \mathrm{MPa}$ & 229,230 \\
\hline
\end{tabular}

AFM, atomic force microscopy; $E$, uniaxial elastic Young's modulus. 
Table 3 Mechanical moduli of distinct cell types.

\begin{tabular}{|c|c|c|c|c|}
\hline Cell type & Technique & Moduli & Moduli values (condition) & Refs. \\
\hline Differentiating MSCs & $\begin{array}{l}\text { Micropipette } \\
\text { aspiration }\end{array}$ & $E$ & $\begin{array}{l}0.89 \mathrm{kPa} \text { (osteogenic) } \\
0.22 \mathrm{kPa} \text { (adipogenic) }\end{array}$ & 78 \\
\hline MSCs & AFM indentation & $E$ & $\begin{array}{l}2.5 \mathrm{kPa}\left(\text { spherical }^{\mathrm{a}}\right) \\
3.2 \mathrm{kPa}\left(\text { spread }^{\mathrm{b}}\right)\end{array}$ & 100 \\
\hline Osteoblasts & AFM indentation & $E$ & $\begin{array}{l}2.6 \mathrm{kPa}\left(\text { spherical }^{\mathrm{a}}\right) \\
6.5 \mathrm{kPa}\left(\text { spread }^{\mathrm{b}}\right)\end{array}$ & 100 \\
\hline Pancreatic cells & AFM indentation & $E$ & $\begin{array}{l}0.54 \mathrm{kPa} \text { (healthy cell) } \\
0.54 \mathrm{kPa} \text { (carcinoma) }\end{array}$ & 5 \\
\hline Cervical epithelial cells & AFM indentation & $E$ & $\begin{array}{l}2.05 \mathrm{kPa} \text { (healthy cell) } \\
2.80 \mathrm{kPa} \text { (carcinoma) }\end{array}$ & 160 \\
\hline Fibroblasts & AFM indentation & $E$ & $0.5-30.0 \mathrm{kPa}$ (cell body) & 71,231 \\
\hline Pleural effusion cells & AFM indentation & $E$ & $\begin{array}{l}0.38 \mathrm{kPa} \text { (metastatic cell) } \\
2.53 \mathrm{kPa} \text { (healthy cell) }\end{array}$ & 161 \\
\hline Lung cells & AFM rheology & $G^{\prime}$ & $\begin{array}{l}0.5 \mathrm{kPa} \text { (alveolar cell) } \\
0.7 \mathrm{kPa} \text { (bronchial cell) }\end{array}$ & 232 \\
\hline Embryonic stem cells & $\begin{array}{l}\text { Magnetic twisting } \\
\text { cytometry }\end{array}$ & $G$ & $\begin{array}{l}0.55 \mathrm{kPa} \text { (naive) } \\
\mathrm{Up} \text { to } 2 \mathrm{kPa} \text { (differentiated) }\end{array}$ & 80 \\
\hline Adipose stem cells & AFM indentation & $E$ & $0.6-1.6 \mathrm{kPa}$ & 77 \\
\hline Smooth muscle cells & AFM indentation & $E$ & $5.9-7.7 \mathrm{kPa}$ & 233 \\
\hline Cardiomyocytes & AFM indentation & $E$ & $41 \mathrm{kPa}$ & 98 \\
\hline Keratinocytes & AFM indentation & $E$ & $120-340 \mathrm{kPa}$ & 234 \\
\hline Kidney proximal tubule cells & AFM indentation & $E$ & $0.35 \mathrm{kPa}$ & 235 \\
\hline Hepatocytes & AFM indentation & $E$ & $0.75-1 \mathrm{kPa}$ & 236 \\
\hline Thyroid cells & AFM indentation & $E$ & $\begin{array}{l}1.2 \mathrm{kPa} \text { (healthy cell) } \\
1.3 \mathrm{kPa} \text { (cancer) }\end{array}$ & 73 \\
\hline Eye lens cells & AFM indentation & $E$ & $\begin{array}{l}4.83 \mathrm{kPa} \text { (nuclear cells) } \\
0.22 \mathrm{kPa} \text { (cortical cells) }\end{array}$ & 237 \\
\hline
\end{tabular}

aSpherical cells have a round morphology owing to a short culture duration. ${ }^{\mathrm{b}}$ Upon continued culture, cells lose their initial spherical morphology and exhibit spread over the surface. AFM, atomic force microscopy; $E$, uniaxial elastic Young's modulus; $G$, shear modulus; $G$ ', shear storage modulus (dynamic); MSC, mesenchymal stem cell. 
Table 4 Mechanical moduli of human tissues.

\begin{tabular}{|c|c|c|c|c|}
\hline Tissue & Dimension & Moduli & Moduli value (condition) & Refs. \\
\hline \multicolumn{5}{|l|}{ Nervous system } \\
\hline Brain & Macroscale & $G$ & $1-3 \mathrm{kPa}$ & $170,238,239$ \\
\hline Spinal cord & Macroscale & $E$ & $1.23 \mathrm{MPa}$ (tensile) & 110 \\
\hline Nerve & Macroscale & $E$ & $5 \mathrm{MPa}$ & 240 \\
\hline \multicolumn{5}{|l|}{ Connective tissue } \\
\hline Bone & Nanoscale & $E$ & $1.28-1.97 \mathrm{GPa}$ & 128 \\
\hline Bone & Macroscale & $E$ & $10.4-20.7 \mathrm{GPa}$ & 92 \\
\hline Cartilage & Macroscale & $G$ & $5.7-6.2 \mathrm{MPa}$ & 241 \\
\hline Adipose tissue & Macroscale & $E$ & $1.6-5.5 \mathrm{kPa}$ & $131,139,242$ \\
\hline Ligament & Macroscale & $E$ & $25-93 \mathrm{MPa}$ & $243-245$ \\
\hline \multicolumn{5}{|l|}{ Muscle tissue } \\
\hline Cardiac muscle & Macroscale & $E$ & $8 \mathrm{kPa}$ & 246 \\
\hline Cardiac muscle & Macroscale & $G$ & $5-50 \mathrm{kPa}$ & 171,247 \\
\hline Skeletal muscle & Macroscale & $E, G$ & $5-170 \mathrm{kPa}$ & $248-251$ \\
\hline \multicolumn{5}{|l|}{$\begin{array}{l}\text { Endothelial or } \\
\text { epithelial tissues }\end{array}$} \\
\hline Skin & Macroscale & $E$ & $\begin{array}{l}60-850 \mathrm{kPa}(35 \mathrm{kPa} \text { dermis, } 2 \\
\mathrm{kPa} \text { hypodermis })\end{array}$ & $\begin{array}{l}111,117,120,25 \\
2\end{array}$ \\
\hline Skin & Nanoscale & $E$ & $\begin{array}{l}4.5 \mathrm{MPa} \text { (epidermis), } 0.1 \mathrm{MPa} \\
\text { (dermis) }\end{array}$ & 141 \\
\hline Lung & Macroscale & $G$ & $0.84-1.50 \mathrm{kPa}$ & 253,254 \\
\hline Lung & Nanoscale & $E$ & $1.96 \mathrm{kPa}$ & 255 \\
\hline \multicolumn{5}{|l|}{ Other organs } \\
\hline Kidney & Macroscale & $G$ & $\begin{array}{l}4 \mathrm{kPa} \text { (cortex), } 5 \mathrm{kPa} \\
\text { (medulla), } 8 \mathrm{kPa} \text { (sinus) }\end{array}$ & 256,257 \\
\hline Spleen & Macroscale & $G$ & $15-20 \mathrm{kPa}$ & $\begin{array}{ll}144-147 \\
\end{array}$ \\
\hline Liver & Macroscale & $E$ & $4.0-6.5 \mathrm{kPa}$ & $258-260$ \\
\hline Liver & Macroscale & $G$ & $2 \mathrm{kPa}$ & 261,262 \\
\hline Thymus $^{\mathrm{a}}$ & Macroscale & $E$ & $2.11 \mathrm{kPa}$ & 131 \\
\hline Thyroid & Macroscale & $E$ & $9-50 \mathrm{kPa}$ & $169,263-265$ \\
\hline Thyroid & Macroscale & $G$ & $1.3-1.9 \mathrm{kPa}$ & 266 \\
\hline Pancreas & Macroscale & $E$ & $2.9 \mathrm{kPa}$ & 267 \\
\hline Pancreas & Macroscale & $G$ & $1.1-2.1 \mathrm{kPa}$ & $223,268,269$ \\
\hline Bladder & Macroscale & $G$ & $\begin{array}{l}50 \mathrm{kPa} \text { (empty) up to } 100 \mathrm{kPa} \\
\text { (full) }\end{array}$ & 270 \\
\hline Cornea & Macroscale & $E$ & $0.2 \mathrm{MPa}$ & 271 \\
\hline Cornea & Nanoscale & $E$ & $7.5-109.8 \mathrm{kPa}^{\mathrm{b}}$ & 272 \\
\hline Lens & Nanoscale & $E$ & $0.4 \mathrm{MPa}$ (capsule) & 273 \\
\hline Lens & Macroscale & $E$ & 2.3-3.3 MPa (capsule) & 122,123 \\
\hline Lens & Macroscale & $G$ & $0.2-10.3 \mathrm{kPa}$ & 124 \\
\hline
\end{tabular}

${ }^{\mathrm{a}}$ Decellularized. ${ }^{\mathrm{b}}$ Distinct layers of the cornea have different moduli, as detailed in Supplementary Table

S1. E, elastic modulus; $G$, shear modulus. 
Figure 1. Main mechanical deformations and representative curves. The main types of mechanical analysis include $\mathbf{a} \mid$ tensile, $\mathbf{b} \mid$ compressive, $\mathbf{c} \mid$ shear and $\mathbf{d} \mid$ torsion deformations. e | Typically, static deformations (such as tensile or strain deformations) yield a complex curve within which distinct regions can be identified, each of which has important mechanical correlates. Young's modulus $(E)$ is calculated as the slope of the stress verus strain curve in the linear (elastic) region. With higher levels of strain, the material enters the plastic domain of the curve, where deformations are no longer reversible and the material deforms permanently until fracture occurs. Alternatively, a dynamic analysis can be performed, in which a strain within the linear (viscoelastic) region is applied repeatedly over time, in cycles often with changes in frequency or temperature, to yield storage $\left(E^{\prime}\right)$ and loss $\left(E^{\prime \prime}\right)$ moduli . The storage modulus is related to elastic deformation of the material whereas the loss modulus represents the energy dissipated by internal structural rearrangements.

Figure 2. The stiffness of living tissues spans a full Pa-GPa range. The literaturereported elastic moduli $(E)$ of tdifferent tissues are reported in the left (logarithmic) scale. Tissues are organized by increasing crescent moduli. Central nervous system (CNS) tissues, as well as most abdominal organs and skin have moduli within the sub$\mathrm{MPa}$ level and as such are generally characterized as soft tissues (in biological terms). Cartilage, ligament, tendon and bone are the stiffest tissues of the human body. For comparison purposes, the moduli of some common tissue engineering materials are included in the graph: $8 \%$ acrylamide gel ${ }^{274}$, tissue culture polystyrene ${ }^{275}$ and titanium (used for dental and bone implants) ${ }^{276}$. Tissue culture polystyrene, the standard cellculture substrate, is clearly stiffer than almost all biological tissues, an important source of error in mechanical analyses derived from in vitro studies. The reported moduli are derived from studies across different animal models and types of deformation, although we have prioritized studies using human tissues and physiological-like deformations (mostly at macroscale dimensions).

Figure 3: Tissue mechanics are altered in disease states. Fibrosis and cancer are the two main disease states in which the mechanical properties of tissues are prominently affected. In both conditions, the desmoplastic deposition and crosslinking of extracellular matrix (ECM) fibres, together with fibroblast proliferation and 
differentiation into myofibroblasts, lead to increased tissue stiffness. These changes are a response to prolonged healing, tissue damage (fibrosis) or neoplastic lesions (cancer). Moreover, in tumours, aberrant cell proliferation compresses the surrounding healthy tissue compartments, leading to mass effects (such as nerve and blood vessel compression) and an increase in solid stress, which further stiffens the local tissue. Additionally, in cancer, malignant cells can further subvert stromal entities in the tumour microenvironment towards a profibrotic phenotype ${ }^{167}$, resulting in increased local fibrosis.

Figure 4: Engineering of life-like tissue mechanics. The ultimate goal of considering stiffness in tissue engineering strategies is the recapitulation of the qualities of living tissue. Static mechanical properties are initially considered by trying to mimic the stiffness and/or softness of the native structure. However, the dynamic nature of biological tissues leads to a need for the incorporation of changes in mechanics (either in space or time). Time-varying mechanics can be obtained by exploiting materials with stress stiffening or stress relaxation responses (whereby the material either stiffens or relaxes in response to a continued duration or increased level of stress, respectively). Alternatively, mechanical deformation can be applied directly to constructs to mimic these properties when the material itself lacks such dynamicity. Space-changing mechanics are found in tissue interfaces such as those found in regions where cartilage is gradually becoming bone. The characteristics of these gradually changing structures can be mimicked by gradients of structure, composition and mechanical properties. 


\section{BOX 1 Standards in mechanical testing}

Standardized protocols must be followed in mechanical analyses if the data so obtained are to be interpreted with a good level of confidence and comparable between different investigational studies. Accordingly, in the past decade, there has been a great effort to introduce standardized methods for the analysis of tissue-engineered products, such as the American Society for Testing and Materials (ASTM) standards developed by committee F04 and related subcommittees, which aim to improve the safety, quality and consistency of these products. Although these standards were not specifically developed for the purpose of performing mechanical tests on human tissues, they can provide guidance for appropriate testing. For example, ASTM F561-19 covers recommendations for the handling and analysis of postmortem tissue and living tissue samples surgically removed from human and animal subjects, whereas ASTM F215013 provides guidance on the selection of appropriate test methods for analyzing the bulk physical, chemical, mechanical and surface properties of such samples. ASTM D63814 , a standard for testing polymeric materials under uniaxial extension, states that it might not be meaningful to compare the results of tests made over widely different loads or time scales. Although biological systems differ substantially from the plastics referred to in ASTM D638-14, when taking a cautious approach we might reasonably extend these concepts to human tissues. Overall, however, the tissue-engineering literature seems to be reluctant to adopt similar standards, or even to attempt to follow existing standards. In most published reports, mechanical tests are either not performed according to any consensus standard, or if they are, the standard followed is rarely referenced. 


\section{BOX 2 Towards a unified description of cellular mechanics.}

The past three decades have seen substantial efforts to define the ruling principle behind cellular mechanics and its consequential effects on mechanotransduction responses and all consequent cellular events (including cell membrane protrusion, adhesion, migration and mitosis). The cellular tensegrity model proposed that the cytoskeleton is a tensioned or prestressed network responsible for maintaining cellular stability, in the same way that tensegrity architecture enables buildings and bridges to stay unchanged and robust for countless years ${ }^{277}$. Subsequently, other researchers hypothesized that cells behaved as a soft glassy material; that is, having time-scale free and frequency scale free rheological behaviour that obeys a weak power-law ${ }^{278}$. This notion became known as the soft glassy rheology (SGR) model, which was later complemented by evidence that at extreme time-scales or frequencies, cellular behaviour deviated from a single power law and showed time-scale dependency ${ }^{279}$. Nevertheless, among its fundamental characteristics, the SGR model implies that cells (in common with other soft glasses) are metastable structures that are naturally out of equilibrium. Although this characteristic is in agreement with the recent description of cortical cell networks as out-of-balance, active gels ${ }^{68}$, some difference exists between the SGR model and a stable, equilibrated tensegrity model. Until now, both models are still employed to describe the distinct phenomena governing cell function: both models suggest that actomyosin pre-stress is the link between cytoskeletal stabilization and power-law modulation of cell behaviour ${ }^{280}$. Nevertheless, a general unification of these models is yet to be established. 


\section{References}

1. Callister, W. D. . J. \& Rethwisch, D. G. Materials Science and Engineering: An Introduction 8th Edition. Wiley (2007). doi:10.1016/0025-5416(87)90343-0

2. Langer, R. \& Vacanti, J. P. Tissue Engineering. Science (80-. ). 260, 920-926 (1993).

3. Discher, D. E., Janmey, P. \& Wang, Y. Tissue Cells Feel and Respond to the Stiffness of Their Substrate Science (80-. ). 310, 1139-1143 (2005).

\section{Seminal work reporting for the first time that mechanics alone affect the behavior of cells.}

4. Yanez, L. Z., Han, J., Behr, B. B., Pera, R. A. R. \& Camarillo, D. B. Human oocyte developmental potential is predicted by mechanical properties within hours after fertilization. Nat. Commun. 7, 1-12 (2016).

5. Cross, S. E., Jin, Y. S., Rao, J. \& Gimzewski, J. K. Nanomechanical analysis of cells from cancer patients. Nat. Nanotechnol. 2, 780-783 (2007).

6. Baumgart, F. \& Cordey, J. Stiffness - An unknown world of mechanical science? Injury 32, 14-23 (2001).

7. Pang, Z., Deeth, H., Sopade, P., Sharma, R. \& Bansal, N. Rheology, texture and microstructure of gelatin gels with and without milk proteins. Food Hydrocoll. 35, 484-493 (2014).

8. Koga, Y., Koga, T., Kinekawa, Y. \& Kitabatake, N. Properties of a Thermostable Emulsion Prepared from Process Whey Protein and Olive Oil; Use as a creamsubstitute and Its Practical Application to Panna-Cotta. J. Cook. Sci. Japan 34, 154-163 (2001).

9. Williams, S. H., Wright, B. W., Truong, V. den, Daubert, C. R. \& Vinyard, C. J. Mechanical properties of foods used in experimental studies of primate masticatory function. Am. J. Primatol. 67, 329-346 (2005).

10. Perry, J. M. G., Bastian, M. L., St Clair, E. \& Hartstone-Rose, A. Maximum ingested food size in captive anthropoids. Am. J. Phys. Anthropol. 158, 92-104 (2015).

11. Callister, W. D. \& Rethwisch, D. G. Materials science and engineering : an introduction.

12. Davis, J. R. (Joseph R. . Tensile testing. (ASM International, 2004).

13. Wong, B. L., Bae, W. C., Gratz, K. R. \& Sah, R. L. Shear deformation kinematics during cartilage articulation: effect of lubrication, degeneration, and 
stress relaxation. Mol. Cell. Biomech. 5, 197-206 (2008).

14. Pothan, L. A., Oommen, Z. \& Thomas, S. Dynamic mechanical analysis of banana fiber reinforced polyester composites. Compos. Sci. Technol. 63, 283-293 (2003).

15. Meyers, M. A. \& Chawla, K. K. Mechanical Behavior of Materials. Mechanical Behavior of Materials (2009).

16. Cross, R. Elastic and viscous properties of Silly Putty. Am. J. Phys. 80, 870-875 (2012).

17. Omari, E. A., Varghese, T., Kliewer, M. A., Harter, J. \& Hartenbach, E. M. Dynamic and quasi-static mechanical testing for characterization of the viscoelastic properties of human uterine tissue. J. Biomech. 48, 1730-6 (2015).

18. Karunaratne, A., Li, S. \& Bull, A. M. J. Nano-scale mechanisms explain the stiffening and strengthening of ligament tissue with increasing strain rate. Sci. Rep. 8, 3707 (2018).

19. Wang, L. \& Liu, X. Characterization of viscoelastic materials by quasi-static and dynamic indentation. Meas. Sci. Technol. 25, 064017 (2014).

20. Schapery, R. A. Two Simple Approximate Methods of Laplace Transform Inversion for Viscoelastic Stress Analysis. (1961).

21. Schapery, R. A. Stress Analysis of Viscoelastic Composite Materials. J. Compos. Mater. 1, 228-267 (1967).

22. Yofe, A. D. Physics at surfaces. Contemp. Phys. 29, 411-414 (1988).

23. Abazari, A. M., Safavi, S. M., Rezazadeh, G. \& Villanueva, L. G. Modelling the size effects on the mechanical properties of micro/nano structures. Sensors (Switzerland) 15, 28543-28562 (2015).

24. McNamara, L. E. et al. The role of microtopography in cellular mechanotransduction. Biomaterials 33, 2835-2847 (2012).

25. Peric, D., de Souza Neto, E. A., Feijóo, R. A., Partovi, M. \& Carneiro Molina, A. J. On micro-to-macro transitions for multi-scale analysis of non-linear heterogeneous materials: unified variational basis and finite element implementation. Int. J. Numer. Methods Eng. 00, 149-170 (2011).

26. Geers, M. G. D., Kouznetsova, V. G. \& Brekelmans, W. A. M. Multi-scale computational homogenization: Trends and challenges. J. Comput. Appl. Math. 234, 2175-2182 (2010).

27. Speirs, D. C. D., de Souza Neto, E. A. \& Perić, D. An approach to the 
mechanical constitutive modelling of arterial tissue based on homogenization and optimization. J. Biomech. 41, 2673-2680 (2008).

28. Hollister, S. J. \& Lin, C. Y. Computational design of tissue engineering scaffolds. Comput. Methods Appl. Mech. Eng. 196, 2991-2998 (2007).

29. Kim, S. H., Turnbull, J. \& Guimond, S. Extracellular matrix and cell signalling: The dynamic cooperation of integrin, proteoglycan and growth factor receptor. $J$. Endocrinol. 209, 139-151 (2011).

30. Miller, C. J. \& Davidson, L. A. The interplay between cell signalling and mechanics in developmental processes. Nat. Rev. Genet. 14, 733-744 (2013).

31. Alcaraz, J. et al. Laminin and biomimetic extracellular elasticity enhance functional differentiation in mammary epithelia. EMBO J. 27, 2829-2838 (2008).

32. Keane, T. J., Horejs, C. M. \& Stevens, M. M. Scarring vs. functional healing: Matrix-based strategies to regulate tissue repair. Adv. Drug Deliv. Rev. 129, 407419 (2018).

33. Sasaki, N. \& Odajima, S. Stress-strain curve and Young's modulus of a collagen molecule as determined by the X-ray diffraction technique. J. Biomech. 29, 655658 (1996).

34. Wenger, M. P. E., Bozec, L., Horton, M. A. \& Mesquidaz, P. Mechanical properties of collagen fibrils. Biophys. J. 93, 1255-1263 (2007).

35. Bornstein, P. \& Sage, H. Structurally Distinct Collagen Types. Annu. Rev. Biochem. 49, 957-1003 (1980).

36. Shoulders, M. D. \& Raines, R. T. Collagen Structure and Stability. Annu. Rev. Biochem. 78, 929-958 (2009).

37. Zhang, W., Huang, Z. L., Liao, S. S. \& Cui, F. Z. Nucleation sites of calcium phosphate crystals during collagen mineralization. J. Am. Ceram. Soc. 86, 10521054 (2003).

38. Herchenhan, A. et al. Tenocyte contraction induces crimp formation in tendonlike tissue. Biomech. Model. Mechanobiol. 11, 449-459 (2012).

39. Hornsby, J. et al. Quantitative multiphoton microscopy of murine urinary bladder morphology during in situ uniaxial loading. Acta Biomater. 64, 59-66 (2017).

40. Wiesinger, H. P., Rieder, F., Kösters, A., Müller, E. \& Seynnes, O. R. Are SportSpecific Profiles of Tendon Stiffness and Cross-Sectional Area Determined by Structural or Functional Integrity? PLoS One 11, 4-6 (2016).

41. Ma, Y., Feng, X., Rogers, J. A., Huang, Y. \& Zhang, Y. Design and application 
of 'J-shaped' stress-strain behavior in stretchable electronics: A review. Lab Chip 17, 1689-1704 (2017).

42. Wagenseil, J. E. \& Mecham, R. P. Elastin in large artery stiffness and hypertension. J. Cardiovasc. Transl. Res. 5, 264-273 (2012).

43. Muiznieks, L. D., Weiss, A. S. \& Keeley, F. W. Structural disorder and dynamics of elastin. Biochem. Cell Biol. 88, 239-250 (2010).

44. Muiznieks, L. D. \& Keeley, F. W. Molecular assembly and mechanical properties of the extracellular matrix: A fibrous protein perspective. Biochim. Biophys. Acta - Mol. Basis Dis. 1832, 866-875 (2013).

45. Ryan, A. J. \& O’Brien, F. J. Insoluble elastin reduces collagen scaffold stiffness, improves viscoelastic properties, and induces a contractile phenotype in smooth muscle cells. Biomaterials 73, 296-307 (2015).

46. Tsamis, A., Krawiec, J. T. \& Vorp, D. A. Elastin and collagen fibre microstructure of the human aorta in ageing and disease: A review. J. R. Soc. Interface 10, (2013).

47. Ahmadzadeh, H., Connizzo, B. K., Freedman, B. R., Soslowsky, L. J. \& Shenoy, V. B. Determining the contribution of glycosaminoglycans to tendon mechanical properties with a modified shear-lag model. J. Biomech. 46, 2497-2503 (2013).

48. Quinn, T. M., Dierickx, P. \& Grodzinsky, A. J. Glycosaminoglycan network geometry may contribute to anisotropic hydraulic permeability in cartilage under compression. J. Biomech. 34, 1483-1490 (2001).

49. Tavakoli Nia, H. et al. Aggrecan nanoscale solid-fluid interactions are a primary determinant of cartilage dynamic mechanical properties. ACS Nano 9, 2614-2625 (2015).

50. Klotzsch, E. et al. Fibronectin forms the most extensible biological fibers displaying switchable force-exposed cryptic binding sites. Proc. Natl. Acad. Sci. 106, 18267-18272 (2009).

51. Dray, N. et al. Cell-fibronectin interactions propel vertebrate trunk elongation via tissue mechanics. Curr. Biol. 23, 1335-1341 (2013).

52. Gautieri, A., Uzel, S., Vesentini, S., Redaelli, A. \& Buehler, M. J. Molecular and mesoscale mechanisms of osteogenesis imperfecta disease in collagen fibrils.

Biophys. J. 97, 857-865 (2009).

53. Mavilio, F. et al. Correction of junctional epidermolysis bullosa by transplantation of genetically modified epidermal stem cells. Nat. Med. 12, 1397- 
1402 (2006).

54. Wagner, J. E. et al. Bone Marrow Transplantation for Recessive Dystrophic Epidermolysis Bullosa. N. Engl. J. Med. 363, 629-639 (2010).

55. Germain, D. P. Clinical and genetic features of vascular Ehlers-Danlos syndrome. Ann. Vasc. Surg. 16, 391-397 (2002).

56. De Paepe, A. \& Malfait, F. The Ehlers-Danlos syndrome, a disorder with many faces. Clin. Genet. 82, 1-11 (2012).

57. Von Erlach, T. C. et al. Cell-geometry-dependent changes in plasma membrane order direct stem cell signalling and fate. Nat. Mater. 17, 237-242 (2018).

58. Kasza, K. E. et al. The cell as a material. Curr. Opin. Cell Biol. 19, 101-107 (2007).

\section{The first outline of cells as a material.}

59. Suresh, S. Biomechanics and biophysics of cancer cells. Acta Mater. 55, 3989 4014 (2007).

60. Fletcher, D. A. \& Mullins, R. D. Cell mechanics and the cytoskeleton. Nature 463, 485-492 (2010).

61. Kumar, S. et al. Viscoelastic retraction of single living stress fibers and its impact on cell shape, cytoskeletal organization, and extracellular matrix mechanics. Biophys. J. 90, 3762-3773 (2006).

62. Salbreux, G., Charras, G. \& Paluch, E. Actin cortex mechanics and cellular morphogenesis. Trends Cell Biol. 22, 536-545 (2012).

\section{Interesting perspective on the cell cortex dynamics.}

63. Ingber, D. E. Tensegrity-based mechanosensing from macro to micro. Prog. Biophys. Mol. Biol. 97, 163-179 (2008).

Complete view on tensegrity in cell mechanics and its parallel to architecture.

64. Ingber, D. E. From mechanobiology to developmentally inspired engineering. Philos. Trans. R. Soc. B Biol. Sci. 373, 1-7 (2018).

65. Mandriota, N. et al. Cellular nanoscale stiffness patterns governed by intracellular forces. Nat. Mater. 18, 1071-1077 (2019)

Evidence of how much influence intracellular forces and states have on the 


\section{local cellular stiffness.}

66. Condeelis, J. Life at the Leading Edge: The Formation of Cell Protrusions. Annu. Rev. Cell Dev. Biol. 9, 411-444 (1993).

67. Charras, G. T., Yarrow, J. C., Horton, M. A., Mahadevan, L. \& Mitchison, T. J. Non-equilibration of hydrostatic pressure in blebbing cells. Nature 435, 365-369 (2005).

68. Prost, J., Jülicher, F. \& Joanny, J. F. Active gel physics. Nat. Phys. 11, 111-117 (2015).

\section{Complete description of the physics of active gels.}

69. Guo, M. et al. Cell volume change through water efflux impacts cell stiffness and stem cell fate. Proc. Natl. Acad. Sci. 114, E8618-E8627 (2017).

70. Lekka, M. \& Laidler, P. Applicability of AFM in cancer detection. Nat. Nanotechnol. 4, 72-72 (2009).

71. Gavara, N. \& Chadwick, R. S. Determination of the elastic moduli of thin samples and adherent cells using conical atomic force microscope tips. Nat. Nanotechnol. 7, 733-736 (2012).

72. Dimitriadis, E. K., Horkay, F., Maresca, J., Kachar, B. \& Chadwick, R. S. Determination of elastic moduli of thin layers of soft material using the atomic force microscope. Biophys. J. 82, 2798-2810 (2002).

73. Rianna, C. \& Radmacher, M. Comparison of viscoelastic properties of cancer and normal thyroid cells on different stiffness substrates. Eur. Biophys. J. 46, 309324 (2017).

74. Kaushik, G., Fuhrmann, A., Cammarato, A. \& Engler, A. J. In situ mechanical analysis of myofibrillar perturbation and aging on soft, bilayered Drosophila myocardium. Biophys. J. 101, 2629-2637 (2011).

75. Tan, J. L. et al. Cells Lying on a bed of microneedles: An approach to isolate mechanical force. Proc. Natl. Acad. Sci. 2002, 1-6 (2003).

76. Tee, S. Y., Fu, J., Chen, C. S. \& Janmey, P. A. Cell shape and substrate rigidity both regulate cell stiffness. Biophys. J. 100, L25-L27 (2011).

77. Gonzalez-Cruz, R. D., Fonseca, V. C. \& Darling, E. M. Cellular mechanical properties reflect the differentiation potential of adipose-derived mesenchymal stem cells. Proc. Natl. Acad. Sci. (2012). doi:10.1073/pnas.1120349109 
78. Yu, H. et al. Mechanical behavior of human mesenchymal stem cells during adipogenic and osteogenic differentiation. Biochem. Biophys. Res. Commun. 393, 150-155 (2010).

79. Norcross, S., Horsley, V., Mertz, A. F., Rosowski, K. A. \& Dufresne, E. R. Edges of human embryonic stem cell colonies display distinct mechanical properties and differentiation potential. Sci. Rep. 5, 1-12 (2015).

80. Poh, Y.-C. et al. Material properties of the cell dictate stress-induced spreading and differentiation in embryonic stem cells. Nat. Mater. 9, 82-88 (2009).

81. Das, R. K., Gocheva, V., Hammink, R., Zouani, O. F. \& Rowan, A. E. Stressstiffening-mediated stem-cell commitment switch in soft responsive hydrogels. Nat. Mater. 15, 318-325 (2015).

82. Leong, K. W., Yim, E. K. F., Kulangara, K., Darling, E. M. \& Guilak, F. Nanotopography-induced changes in focal adhesions, cytoskeletal organization, and mechanical properties of human mesenchymal stem cells. Biomaterials 31, 1299-1306 (2009).

83. Conte, V. et al. Control of cell-cell forces and collective cell dynamics by the intercellular adhesome. Nat. Cell Biol. 17, 409-420 (2015).

84. Latorre, E. et al. Active superelasticity in three-dimensional epithelia of controlled shape. Nature 563, 203-208 (2018).

85. Vincent, R. et al. Active Tensile Modulus of an Epithelial Monolayer. Phys. Rev. Lett. 115, 1-5 (2015).

86. Charras, G. \& Yap, A. S. Tensile Forces and Mechanotransduction at Cell-Cell Junctions. Curr. Biol. 28, R445-R457 (2018).

87. Khalilgharibi, N. et al. Stress relaxation in epithelial monolayers is controlled by the actomyosin cortex. Nat. Phys. (2019). doi:10.1038/s41567-019-0516-6

88. Gonzalez-Rodriguez, D., Guevorkian, K., Douezan, S. \& Brochard-Wyart, F. Soft matter models of developing tissues and tumors. Science (80-. ). 338, 910 917 (2012).

89. Serwane, F. et al. In vivo quantification of spatially varying mechanical properties in developing tissues. Nat. Methods 14, 181-186 (2017).

90. Mongera, A. et al. A fluid-to-solid jamming transition underlies vertebrate body axis elongation. Nature 561, 401-405 (2018).

91. Stooke-Vaughan, G. A. \& Campàs, O. Physical control of tissue morphogenesis across scales. Curr. Opin. Genet. Dev. 51, 111-119 (2018). 
92. Rho, J. Y., Ashman, R. B. \& Turner, C. H. Young's modulus of trabecular and cortical bone material: Ultrasonic and microtensile measurements. J. Biomech. 26, 111-119 (1993).

93. McDonald, S. J. et al. Early fracture callus displays smooth muscle-like viscoelastic properties ex vivo: Implications for fracture healing. J. Orthop. Res. 27, 1508-1513 (2009).

94. Chaudhuri, O. et al. Hydrogels with tunable stress relaxation regulate stem cell fate and activity. Nat. Mater. 15, 326-334 (2015).

\section{Seminal work on the effect of controlled 3D stress relaxation in the behavior of stem cells.}

95. Chlasta, J. et al. Variations in basement membrane mechanics are linked to epithelial morphogenesis. Development 144, 4350-4362 (2017).

96. Vuong-Brender, T. T. K., Suman, S. K. \& Labouesse, M. The apical ECM preserves embryonic integrity and distributes mechanical stress during morphogenesis. Development 144, 4336-4349 (2017).

97. Nerurkar, N. L., Lee, C. H., Mahadevan, L. \& Tabin, C. J. Molecular control of macroscopic forces drives formation of the vertebrate hindgut. Nature $\mathbf{5 6 5}$, 480484 (2019).

98. Benech, J. C. et al. Diabetes increases stiffness of live cardiomyocytes measured by atomic force microscopy nanoindentation. Am. J. Physiol. Physiol. 307, C910-C919 (2014).

99. Somlyo, A. P. et al. Ultrastructure, function and composition of smooth muscle. Ann. Biomed. Eng. (1983). doi:10.1007/BF02364087

100. Darling, E. M., Topel, M., Zauscher, S., Vail, T. P. \& Guilak, F. Viscoelastic properties of human mesenchymally-derived stem cells and primary osteoblasts, chondrocytes, and adipocytes. J. Biomech. 41, 454-464 (2008).

101. Li, X., Das, A. \& Bi, D. Mechanical Heterogeneity in Tissues Promotes Rigidity and Controls Cellular Invasion. Phys. Rev. Lett. 123, 058101 (2019).

102. Roduit, C. et al. Elastic membrane heterogeneity of living cells revealed by stiff nanoscale membrane domains. Biophys. J. 94, 1521-1532 (2008).

103. Marturano, J. E. et al. Embryonically inspired scaffolds regulate tenogenically differentiating cells. J. Biomech. 49, 3281-3288 (2016).

104. Sotres, J., Jankovskaja, S., Wannerberger, K. \& Arnebrant, T. Ex-Vivo Force 
Spectroscopy of Intestinal Mucosa Reveals the Mechanical Properties of Mucus Blankets. Sci. Rep. 7, 1-14 (2017).

105. Tyler, W. J. The mechanobiology of brain function. Nat. Rev. Neurosci. 13, 867878 (2012).

106. McKee, C. T., Last, J. A., Russell, P. \& Murphy, C. J. Indentation Versus Tensile Measurements of Young's Modulus for Soft Biological Tissues. Tissue Eng. Part B Rev. 17, 155-164 (2011).

107. Does, M. D. et al. Insights into reference point indentation involving human cortical bone: Sensitivity to tissue anisotropy and mechanical behavior. J. Mech. Behav. Biomed. Mater. 37, 174-185 (2014).

108. Haase, K. \& Pelling, A. Investigating cell mechanics with atomic force microscopy. J. R. Soc. Interface 1-7 (2016). doi:10.1098/rsif

109. Saxena, T., Gilbert, J., Stelzner, D. \& Hasenwinkel, J. Mechanical Characterization of the Injured Spinal Cord after Lateral Spinal Hemisection Injury in the Rat. J. Neurotrauma 29, 1747-1757 (2012).

110. Oakland, R. J., Hall, R. M., Wilcox, R. K. \& Barton, D. C. The biomechanical response of spinal cord tissue to uniaxial loading. Proc. Inst. Mech. Eng. Part H J. Eng. Med. 220, 489-492 (2006).

111. Pailler-Mattei, C., Bec, S. \& Zahouani, H. In vivo measurements of the elastic mechanical properties of human skin by indentation tests. Med. Eng. Phys. 30, 599-606 (2008).

112. Pissarenko, A. et al. Tensile behavior and structural characterization of pig dermis. Acta Biomater. 86, 77-95 (2019).

113. Iskratsch, T., Wolfenson, H. \& Sheetz, M. P. Appreciating force and shape - the rise of mechanotransduction in cell biology. Nat. Rev. Mol. Cell Biol. 15, 825833 (2014).

114. Guo, K. \& Buehler, M. J. Nature's Way: Hierarchical Strengthening through Weakness. Matter 1, 302-303 (2019).

115. Ramakrishna, S., Mayer, J., Wintermantel, E. \& Leong, K. W. Biomedical applications of polymer-composite materials: a review. Compos. Sci. Technol. 61, 1189-1224 (2001).

116. Zhang, G. et al. Development of tendon structure and function: regulation of collagen fibrillogenesis. J. Musculoskelet. Neuronal Interact. 5, 5-21 (2005).

117. Agache, P. G., Monneur, C., Leveque, J. L. \& De Rigal, J. Mechanical properties 
and Young's modulus of human skin in vivo. Arch. Dermatol. Res. 269, 221-232 (1980).

118. Menon, G. K. New insights into skin structure: scratching the surface. Adv. Drug Deliv. Rev. 54, S3-S17 (2002).

119. Skulborstad, A. J., Swartz, S. M. \& Goulbourne, N. C. Biaxial mechanical characterization of bat wing skin. Bioinspiration and Biomimetics 10, 36004 (2015).

120. Hamasaki, T., Yamaguchi, T. \& Iwamoto, M. Estimating the influence of agerelated changes in skin stiffness on tactile perception for static stimulations. $J$. Biomech. Sci. Eng. 13, 1-12 (2018).

121. Cui, J., Lee, C. H., Delbos, A., McManus, J. J. \& Crosby, A. J. Cavitation rheology of the eye lens. Soft Matter 7, 7827-7831 (2011).

122. Krag, S. \& Andreassen, T. T. Mechanical Properties of the Human Posterior Lens Capsule. Investig. Opthalmology Vis. Sci. 44, 691 (2003).

123. Danielsen, C. C. Tensile mechanical and creep properties of Descemet's membrane and lens capsule. Exp. Eye Res. 79, 343-350 (2004).

124. Besner, S., Scarcelli, G., Pineda, R. \& Yun, S. H. In vivo brillouin analysis of the aging crystalline lens. Investig. Ophthalmol. Vis. Sci. 57, 5093-5100 (2016).

125. Tenorio, L. E. M., Devine, K. J., Lee, J., Kowalewski, T. M. \& Barocas, V. H. Biomechanics of human parietal pleura in uniaxial extension. J. Mech. Behav. Biomed. Mater. 75, 330-335 (2017).

126. Davis, N. F. et al. Urinary Bladder vs Gastrointestinal Tissue: A Comparative Study of Their Biomechanical Properties for Urinary Tract Reconstruction. Urology 113, 235-240 (2018).

127. Faingold, A. et al. The effect of hydration on mechanical anisotropy, topography and fibril organization of the osteonal lamellae. J. Biomech. 47, 367-372 (2014).

128. Milovanovic, P. et al. Age-related deterioration in trabecular bone mechanical properties at material level: Nanoindentation study of the femoral neck in women by using AFM. Exp. Gerontol. 47, 154-159 (2012).

129. Melo, E. et al. Effects of the decellularization method on the local stiffness of acellular lungs. Tissue Eng. Part C. Methods 20, 412-22 (2014).

130. Peloso, A. et al. The human pancreas as a source of protolerogenic extracellular matrix scaffold for a new-generation bioartificial endocrine pancreas. Ann. Surg. 264, 169-179 (2016). 
131. Omidi, E. et al. Characterization and assessment of hyperelastic and elastic properties of decellularized human adipose tissues. J. Biomech. 47, 3657-3663 (2014).

132. Ocal, S., Ozcan, U. M., Basdogan, I. \& Basdogan, C. Effect of Preservation Period on the Viscoelastic Material Properties of Soft Tissues With Implications for Liver Transplantation. J. Biomech. Eng. 132, 101007 (2010).

133. Yamashita, J., Furman, B. R., Rawls, H. R., Wang, X. \& Agrawal, C. M. The use of dynamic mechanical analysis to assess the viscoelastic properties of human cortical bone. J. Biomed. Mater. Res. 58, 47-53 (2001).

134. Buckwalter, J. A. \& Mankin, H. J. Articular cartilage: degeneration and osteoarthritis, repair, regeneration, and transplantation. Instructional course lectures 47, 487-504 (1998).

135. Zhu, W., Mow, V. C., Koob, T. J. \& Eyre, D. R. Viscoelastic shear properties of articular cartilage and the effects of glycosidase treatments. J. Orthop. Res. 11, 771-781 (1993).

136. Nickien, M., Thambyah, A. \& Broom, N. D. How a decreased fibrillar interconnectivity influences stiffness and swelling properties during early cartilage degeneration. J. Mech. Behav. Biomed. Mater. 75, 390-398 (2017).

137. Brommer, H. et al. Functional consequences of cartilage degeneration in the equine metacarpophalangeal joint: quantitative assessment of cartilage stiffness. Equine Vet. J. 37, 462-7 (2005).

138. Kamiya, A. \& Togawa, T. Adaptive regulation of wall shear stress to flow change in the canine carotid artery. Am. J. Physiol. 239, H14-21 (1980).

139. Alkhouli, N. et al. The mechanical properties of human adipose tissues and their relationships to the structure and composition of the extracellular matrix. AJP Endocrinol. Metab. 305, E1427-E1435 (2013).

140. Wood, L. K. \& Brooks, S. V. Ten weeks of treadmill running decreases stiffness and increases collagen turnover in tendons of old mice. J. Orthop. Res. 34, 346353 (2016).

141. Peñuela, L. et al. Atomic force microscopy for biomechanical and structural analysis of human dermis: A complementary tool for medical diagnosis and therapy monitoring. Exp. Dermatol. 27, 150-155 (2018).

142. Crichton, M. L. et al. The viscoelastic, hyperelastic and scale dependent behaviour of freshly excised individual skin layers. Biomaterials 32, 4670-4681 
(2011).

143. Lampi, M. C. \& Reinhart-King, C. A. Targeting extracellular matrix stiffness to attenuate disease: From molecular mechanisms to clinical trials. Sci. Transl. Med. 10, eaao0475 (2018).

144. Stefanescu, H. et al. Spleen stiffness measurement using fibroscan for the noninvasive assessment of esophageal varices in liver cirrhosis patients. $J$. Gastroenterol. Hepatol. 26, 164-170 (2011).

145. $\mathrm{Hu}, \mathrm{X}$. et al. Indirect prediction of liver fibrosis by quantitative measurement of spleen stiffness using the fibroscan system. J. Ultrasound Med. 33, 73-81 (2014).

146. Veiga, Z. S. T. et al. Transient elastography evaluation of hepatic and spleen stiffness in patients with hepatosplenic schistosomiasis. Eur. J. Gastroenterol. Hepatol. 29, 730-735 (2017).

147. Pawluś, A. et al. Shear wave elastography of the spleen: evaluation of spleen stiffness in healthy volunteers. Abdom. Radiol. 41, 2169-2174 (2016).

148. Chien, C. H. et al. Transient elastography for spleen stiffness measurement in patients with cirrhosis role in degree of thrombocytopenia. J. Ultrasound Med. 35, 1849-1857 (2016).

149. Kalli, M. \& Stylianopoulos, T. Defining the Role of Solid Stress and Matrix Stiffness in Cancer Cell Proliferation and Metastasis. Front. Oncol. 8, (2018).

150. Mancini, M. L. \& Sonis, S. T. Mechanisms of cellular fibrosis associated with cancer regimen-related toxicities. Front. Pharmacol. 5 MAR, 1-9 (2014).

151. Coelho, N. M. \& McCulloch, C. A. Contribution of collagen adhesion receptors to tissue fibrosis. Cell Tissue Res. 365, 521-538 (2016).

152. Martinez, F. J. et al. Idiopathic pulmonary fibrosis Review. Nat. Rev. Dis. Prim. 3, 17074 (2017).

153. Meng, X. M., Nikolic-Paterson, D. J. \& Lan, H. Y. Inflammatory processes in renal fibrosis. Nat. Rev. Nephrol. 10, 493-503 (2014).

154. Tsochatzis, E. A., Bosch, J. \& Burroughs, A. K. Liver cirrhosis. Lancet 383, 1749-1761 (2014).

155. Li, Q., Chen, L. \& Zhou, Y. Diagnostic accuracy of liver stiffness measurement in chronic hepatitis B patients with normal or mildly elevated alanine transaminase levels. Sci. Rep. 8, 1-7 (2018).

156. Ogawa, S. et al. Relationship between liver tissue stiffness and histopathological findings analyzed by shear wave elastography and compression testing in rats 
with non-alcoholic steatohepatitis. J. Med. Ultrason. 43, 355-360 (2016).

157. Pang, J. X. Q. et al. Liver stiffness by transient elastography predicts liver-related complications and mortality in patients with chronic liver disease. PLoS One 9, $1-9(2014)$.

158. Desai, S. S. et al. Physiological ranges of matrix rigidity modulate primary mouse hepatocyte function in part through hepatocyte nuclear factor 4 alpha. Hepatology 64, 261-275 (2016).

159. Li, Q. S., Lee, G. Y. H., Ong, C. N. \& Lim, C. T. AFM indentation study of breast cancer cells. Biochem. Biophys. Res. Commun. 374, 609-613 (2008).

160. Gaikwad, R. M., Woodworth, C. D., Sokolov, I., Subba-Rao, V. \& Iyer, S. Atomic force microscopy detects differences in the surface brush of normal and cancerous cells. Nat. Nanotechnol. 4, 389-393 (2009).

161. Wong, R. et al. AFM-based analysis of human metastatic cancer cells. Nanotechnology 19, 384003 (2008).

162. Lekka, M. Discrimination Between Normal and Cancerous Cells Using AFM. Bionanoscience 6, 65-80 (2016).

163. Maciaszek, J. L. \& Lykotrafitis, G. Sickle cell trait human erythrocytes are significantly stiffer than normal. J. Biomech. 44, 657-661 (2011).

164. Lin, H.-H. H.-K. et al. Mechanical phenotype of cancer cells: cell softening and loss of stiffness sensing. Oncotarget 6, (2015).

165. Gilkes, D. M. et al. Hypoxia-inducible factors mediate coordinated RhoAROCK1 expression and signaling in breast cancer cells. Proc. Natl. Acad. Sci. 111, E384-E393 (2014).

166. Dvorak, H. F. Tumors: wounds that do not heal. Similarities between tumor stroma generation and wound healing. N. Engl. J. Med. 315, 1650-1659 (1986).

167. Dias Carvalho, P. et al. KRAS Oncogenic Signaling Extends beyond Cancer Cells to Orchestrate the Microenvironment. Cancer Res. 1-9 (2017). doi:10.1158/0008-5472.CAN-17-2084

168. Huang, S. \& Ingber, D. E. Cell tension, matrix mechanics, and cancer development. Cancer Cell 8, 175-176 (2005).

169. Lyshchik, A. et al. Elastic Moduli Of Thyroid Tissues Under Compression. Ultrason. Imaging 110, 101-110 (2005).

170. Murphy, M. C. et al. Regional brain stiffness changes across the Alzheimer's disease spectrum. NeuroImage Clin. 10, 283-290 (2016). 
171. Chaturvedi, R. R. et al. Passive stiffness of myocardium from congenital heart disease and implications for diastole. Circulation 121, 979-988 (2010).

172. Vardakastani, V. et al. Increased intra-cortical porosity reduces bone stiffness and strength in pediatric patients with osteogenesis imperfecta. Bone 69, 61-67 (2014).

173. Ye, K. et al. Matrix Stiffness and Nanoscale Spatial Organization of CellAdhesive Ligands Direct Stem Cell Fate. Nano Lett. 15, 4720-4729 (2015).

174. Zhou, Q. et al. Development of a Novel Orthogonal Double Gradient for HighThroughput Screening of Mesenchymal Stem Cells-Materials Interaction. Adv. Mater. Interfaces 5, 4-11 (2018).

175. Garreta, E. et al. Fine tuning the extracellular environment accelerates the derivation of kidney organoids from human pluripotent stem cells. Nat. Mater. 18, (2019).

176. Uynuk-Ool, T. et al. The geometrical shape of mesenchymal stromal cells measured by quantitative shape descriptors is determined by the stiffness of the biomaterial and by cyclic tensile forces. J. Tissue Eng. Regen. Med. (2017). doi:10.1002/term.2263

177. Branco da Cunha, C. et al. Influence of the stiffness of three-dimensional alginate/collagen-I interpenetrating networks on fibroblast biology. Biomaterials 35, 8927-8936 (2014).

178. Xie, J. et al. Substrate elasticity regulates adipose-derived stromal cell differentiation towards osteogenesis and adipogenesis through $\beta$-catenin transduction. Acta Biomater. 79, 83-95 (2018).

179. Lv, H. et al. Biomaterial stiffness determines stem cell fate. Life Sci. 178, 42-48 (2017).

180. Sun, A. X. et al. Chondrogenesis of human bone marrow mesenchymal stem cells in 3-dimensional, photocrosslinked hydrogel constructs: Effect of cell seeding density and material stiffness. Acta Biomater. 58, 302-311 (2016).

181. Hadden, W. J. et al. Stem cell migration and mechanotransduction on linear stiffness gradient hydrogels. Proc. Natl. Acad. Sci. 114, 5647-5652 (2017).

182. Xi, W., Saw, T. B., Delacour, D., Lim, C. T. \& Ladoux, B. Material approaches to active tissue mechanics. Nat. Rev. Mater. 4, 23-44 (2019).

183. Chaudhuri, O. et al. Substrate stress relaxation regulates cell spreading. Nat. Commun. 1-7 (2015). doi:10.1038/ncomms7365 
184. Guvendiren, M. \& Burdick, J. A. Stiffening hydrogels to probe short- and longterm cellular responses to dynamic mechanics. Nat. Commun. 3, 792-799 (2012).

185. Storm, C., Pastore, J. J., MacKintosh, F. C., Lubensky, T. C. \& Janmey, P. A. Nonlinear elasticity in biological gels. Nature 435, 191-194 (2005).

186. Kouwer, P. H. J. et al. Responsive biomimetic networks from polyisocyanopeptide hydrogels. Nature 493, 651-655 (2013).

187. de Almeida, P. et al. Cytoskeletal stiffening in synthetic hydrogels. Nat. Commun. 10, 2-9 (2019).

\section{Seminal work where hydrogels with cytoskeletal-like stress stiffening are obtained.}

188. Dhume, R. Y. \& Barocas, V. H. Emergent structure-dependent relaxation spectra in viscoelastic fiber networks in extension. Acta Biomater. 87, 245-255 (2019).

189. Lee, H. P., Gu, L., Mooney, D. J., Levenston, M. E. \& Chaudhuri, O. Mechanical confinement regulates cartilage matrix formation by chondrocytes. Nat. Mater. 16, 1243-1251 (2017).

190. Kim, B. S., Nikolovski, J., Bonadio, J. \& Mooney, D. J. Cyclic mechanical strain regulates the development of engineered smooth muscle tissue. Nat. Biotechnol. 17, 979-983 (1999).

191. Cochis, A. et al. Bioreactor mechanically guided 3D mesenchymal stem cell chondrogenesis using a biocompatible novel thermo-reversible methylcellulosebased hydrogel. Sci. Rep. 7, 45018 (2017).

192. Chu, S.-Y. et al. Mechanical stretch induces hair regeneration through the alternative activation of macrophages. Nat. Commun. 10, 1524 (2019).

193. Lee, J. K. et al. Tension stimulation drives tissue formation in scaffold-free systems. Nat. Mater. 16, 864-873 (2017).

194. Tsimbouri, P. M. et al. Stimulation of 3D osteogenesis by mesenchymal stem cells using a nanovibrational bioreactor. Nat. Biomed. Eng. 1, 758-770 (2017).

195. Wisdom, K. M. et al. Matrix mechanical plasticity regulates cancer cell migration through confining microenvironments. Nat. Commun. 9, 4144 (2018).

196. Ionescu, A. M. et al. 4D Corneal Tissue Engineering: Achieving TimeDependent Tissue Self-Curvature through Localized Control of Cell Actuators. Adv. Funct. Mater. 1807334, 1807334 (2019). 
197. Loebel, C., Mauck, R. L. \& Burdick, J. A. Local nascent protein deposition and remodelling guide mesenchymal stromal cell mechanosensing and fate in threedimensional hydrogels. Nat. Mater. 18, 883-891 (2019).

\section{Three important works that serve as foundation for our definition of biolabile environments, showing the importance of allowing cells to 'master their fate'.}

198. Qiao, E. L., Kumar, S. \& Schaffer, D. V. Mastering their own fates through the matrix. Nat. Mater. 18, 779-780 (2019).

199. Vert, M., Li, S. M., Spenlehauer, G. \& Guerin, P. Bioresorbability and biocompatibility of aliphatic polyesters. J. Mater. Sci. ... 3, 432-446 (1992).

200. Hutmacher, D. W. Scaffolds in tissue engineering bone and cartilage. Biomaterials 21, 2529-2543 (2000).

201. Deringer, V. L., Caro, M. A. \& Csányi, G. Machine Learning Interatomic Potentials as Emerging Tools for Materials Science. Adv. Mater. 1902765, 1902765 (2019).

202. Ansari, S., Khorshidi, S. \& Karkhaneh, A. Engineering of gradient osteochondral tissue: From nature to lab. Acta Biomater. 87, 41-54 (2019).

203. Silva, E. D. et al. Multifunctional magnetic-responsive hydrogels to engineer tendon-to-bone interface. Nanomedicine Nanotechnology, Biol. Med. 14, 23752385 (2018).

204. Calejo, I., Costa-Almeida, R., Reis, R. L. \& Gomes, M. E. A Textile Platform Using Continuous Aligned and Textured Composite Microfibers to Engineer Tendon-to-Bone Interface Gradient Scaffolds. Adv. Healthc. Mater. 1900200, 1900200 (2019).

205. Ribeiro, V. P. et al. Enzymatically Cross-Linked Silk Fibroin-Based Hierarchical Scaffolds for Osteochondral Regeneration. ACS Appl. Mater. Interfaces 11, 3781-3799 (2019).

206. Canadas, R. F. et al. Biochemical Gradients to Generate 3D Heterotypic-Like Tissues with Isotropic and Anisotropic Architectures. Adv. Funct. Mater. 28, 112 (2018).

207. Calejo, I., Costa-Almeida, R., Reis, R. L. \& Gomes, M. E. A Physiology-Inspired Multifactorial Toolbox in Soft-to-Hard Musculoskeletal Interface Tissue Engineering. Trends Biotechnol. 1-15 (2019). doi:10.1016/j.tibtech.2019.06.003

208. Grigoryan, B. et al. Multivascular networks and functional intravascular 
topologies within biocompatible hydrogels. Science (80-. ). 364, 458-464 (2019).

209. Chimene, D., Lennox, K. K., Kaunas, R. R. \& Gaharwar, A. K. Advanced Bioinks for 3D Printing: A Materials Science Perspective. Ann. Biomed. Eng. 44, 2090-2102 (2016).

210. Bertoldi, K., Vitelli, V., Christensen, J. \& Van Hecke, M. Flexible mechanical metamaterials. Nat. Rev. Mater. 2, (2017).

211. Frenzel, T., Kadic, M. \& Wegener, M. Three-dimensional mechanical metamaterials with a twist. Science (80-. ). 358, 1027-1032 (2017).

212. Zhao, Z., Fang, R., Rong, Q. \& Liu, M. Bioinspired Nanocomposite Hydrogels with Highly Ordered Structures. Adv. Mater. 29, 1-16 (2017).

213. Chen, T., Bakhshi, H., Liu, L., Ji, J. \& Agarwal, S. Combining 3D Printing with Electrospinning for Rapid Response and Enhanced Designability of Hydrogel Actuators. Adv. Funct. Mater. 28, 3-9 (2018).

214. Brown, A. L. et al. 22 Week assessment of bladder acellular matrix as a bladder augmentation material in a porcine model. Biomaterials 23, 2179-2190 (2002).

215. Barak, M. M. \& Black, M. A. A novel use of 3D printing model demonstrates the effects of deteriorated trabecular bone structure on bone stiffness and strength. $J$. Mech. Behav. Biomed. Mater. 78, 455-464 (2018).

216. Ramadan, S., Paul, N. \& Naguib, H. E. Standardized static and dynamic evaluation of myocardial tissue properties. Biomed. Mater. 12, 025013 (2017).

217. Yoo, L., Gupta, V., Lee, C., Kavehpore, P. \& Demer, J. L. Viscoelastic properties of bovine orbital connective tissue and fat : constitutive models. Biomech. Model. Mechanobiol. 10, 901-914 (2012).

218. Schachar, R. A., Chan, R. W. \& Fu, M. Viscoelastic properties of fresh human lenses under 40 years of age: implications for the aetiology of presbyopia. Br. J. Ophthalmol. 95, 1010-1013 (2011).

219. Ozawa, H., Matsumoto, T., Ohashi, T., Sato, M. \& Kokubun, S. Comparison of spinal cord gray matter and white matter softness: measurement by pipette aspiration method. J. Neurosurg. Spine 95, 221-224 (2001).

220. Lee, L. M. \& Liu, A. P. The Application of Micropipette Aspiration in Molecular Mechanics of Single Cells. J. Nanotechnol. Eng. Med. 5, 040902 (2014).

221. Moshtagh, P. R., Pouran, B., Korthagen, N. M., Zadpoor, A. A. \& Weinans, H. Guidelines for an optimized indentation protocol for measurement of cartilage stiffness: The effects of spatial variation and indentation parameters. J. Biomech. 
49, 3602-3607 (2016).

222. Uriarte, J. J. et al. Early impairment of lung mechanics in a murine model of marfan syndrome. PLoS One 11, 1-19 (2016).

223. Shi, Y., Glaser, K. J., Venkatesh, S. K., Ben-Abraham, E. I. \& Ehman, R. L. Feasibility of using 3D MR elastography to determine pancreatic stiffness in healthy volunteers. J. Magn. Reson. Imaging 41, 369-375 (2015).

224. Murphy, M. C. et al. Measuring the characteristic topography of brain stiffness with magnetic resonance elastography. PLoS One 8, 1-14 (2013).

225. Anvari, A., Dhyani, M., Stephen, A. E. \& Samir, A. E. Reliability of shear-wave elastography estimates of the young modulus of tissue in follicular thyroid neoplasms. Am. J. Roentgenol. 206, 609-616 (2016).

226. Dutov, P., Antipova, O., Varma, S., Orgel, J. P. R. O. \& Schieber, J. D. Measurement of elastic modulus of collagen type i single fiber. PLoS One 11, 113 (2016).

227. Li, W. et al. Fibrin Fiber Stiffness Is Strongly Affected by Fiber Diameter, but Not by Fibrinogen Glycation. Biophys. J. 110, 1400-1410 (2016).

228. Collet, J.-P., Shuman, H., Ledger, R. E., Lee, S. \& Weisel, J. W. The elasticity of an individual fibrin fiber in a clot. Proc. Natl. Acad. Sci. 102, 9133-9137 (2005).

229. Aaron, B. B. \& Gosline, J. M. Elastin as a random-network elastomer: A mechanical and optical analysis of single elastin fibers. Biopolymers 20, 12471260 (1981).

230. Gosline, J. et al. Elastic proteins: Biological roles and mechanical properties. Philos. Trans. R. Soc. B Biol. Sci. 357, 121-132 (2002).

231. Zahn, J. T. et al. Age-dependent changes in microscale stiffness and mechanoresponses of cells. Small 7, 1480-1487 (2011).

232. Alcaraz, J. et al. Microrheology of human lung epithelial cells measured by atomic force microscopy. Biophys. J. 84, 2071-2079 (2003).

233. Nakamura, K. et al. Altered nano/micro-order elasticity of pulmonary artery smooth muscle cells of patients with idiopathic pulmonary arterial hypertension. Int. J. Cardiol. 140, 102-107 (2010).

234. Lulevich, V., Yang, H. ya, Isseroff, R. R. \& Liu, G. yu. Single cell mechanics of keratinocyte cells. Ultramicroscopy 110, 1435-1442 (2010).

235. Siamantouras, E., Hills, C. E., Squires, P. E. \& Liu, K. K. Quantifying cellular mechanics and adhesion in renal tubular injury using single cell force 
spectroscopy. Nanomedicine Nanotechnology, Biol. Med. 12, 1013-1021 (2016).

236. Sun, S., Song, Z., Cotler, S. J. \& Cho, M. Biomechanics and functionality of hepatocytes in liver cirrhosis. J. Biomech. 47, 2205-2210 (2014).

237. Hozic, A., Rico, F., Colom, A., Buzhynskyy, N. \& Scheuring, S.

Nanomechanical characterization of the stiffness of eye lens cells: a pilot study. Invest. Ophthalmol. Vis. Sci. 53, 2151-2156 (2012).

238. Kolipaka, A. et al. Magnetic resonance elastography to estimate brain stiffness: Measurement reproducibility and its estimate in pseudotumor cerebri patients. Clin. Imaging 51, 114-122 (2018).

239. Arani, A. et al. Measuring the effects of aging and sex on regional brain stiffness with MR elastography in healthy older adults. Neuroimage 111, 59-64 (2015).

240. Ma, Z. et al. In vitro and in vivo mechanical properties of human ulnar and median nerves. J. Biomed. Mater. Res. - Part A 101 A, 2718-2725 (2013).

241. Robinson, D. L. et al. Mechanical properties of normal and osteoarthritic human articular cartilage. J. Mech. Behav. Biomed. Mater. 61, 96-109 (2016).

242. Comley, K. \& Fleck, N. A. A micromechanical model for the Young's modulus of adipose tissue. Int. J. Solids Struct. 47, 2982-2990 (2010).

243. Savelberg, H. H. C. M., Kooloos, J. G. M., Huiskes, R. \& Kauer, J. M. G. Stiffness of the ligaments of the human wrist joint. J. Biomech. 25, 369-376 (1992).

244. Przybylski, G. J., Carlin, G. J., Patel, P. R. \& Woo, S. L. Y. Human anterior and posterior cervical longitudinal ligaments possess similar tensile properties. $J$. Orthop. Res. 14, 1005-1008 (1996).

245. Pintar, F. A. Geometric and Mechanical Properties of Human Cervical. J. Biomed. Eng. 122, 623-629 (2000).

246. Arani, A. et al. Cardiac MR elastography for quantitative assessment of elevated myocardial stiffness in cardiac amyloidosis. J. Magn. Reson. Imaging 46, 13611367 (2017).

247. Domian, I. J., Yu, H. \& Mittal, N. On Materials for Cardiac Tissue Engineering. Adv. Healthc. Mater. 6, 1-3 (2017).

248. Eby, S. F. et al. Shear wave elastography of passive skeletal muscle stiffness: Influences of sex and age throughout adulthood. Clin. Biomech. 30, 22-27 (2015).

249. Leong, H. T., Hug, F. \& Fu, S. N. Increased Upper Trapezius Muscle Stiffness in 
Overhead Athletes with Rotator Cuff Tendinopathy. PLoS One 11, e0155187 (2016).

250. Brandenburg, J. E. et al. Feasibility and reliability of quantifying passive muscle stiffness in young children by using shear wave ultrasound elastography. $J$. Ultrasound Med. 34, 663-670 (2015).

251. Souron, R. et al. Sex differences in active tibialis anterior stiffness evaluated using supersonic shear imaging. J. Biomech. 49, 3534-3537 (2016).

252. Wang, L., Yan, F., Yang, Y., Xiang, X. \& Qiu, L. Quantitative Assessment of Skin Stiffness in Localized Scleroderma Using Ultrasound Shear-Wave Elastography. Ultrasound Med. Biol. 43, 1339-1347 (2017).

253. Marinelli, J. P. et al. Quantitative assessment of lung stiffness in patients with interstitial lung disease using MR elastography. J. Magn. Reson. Imaging 46, 365-374 (2017).

254. Mariappan, Y. K. et al. Estimation of the absolute shear stiffness of human lung parenchyma using 1h spin echo, echo planar MR elastography. J. Magn. Reson. Imaging 40, 1230-1237 (2014).

255. Booth, A. J. et al. Acellular normal and fibrotic human lung matrices as a culture system for in vitro investigation. Am. J. Respir. Crit. Care Med. 186, 866-876 (2012).

256. Bensamoun, S. F., Robert, L., Leclerc, G. E., Debernard, L. \& Charleux, F. Stiffness imaging of the kidney and adjacent abdominal tissues measured simultaneously using magnetic resonance elastography. Clin. Imaging 35, 284287 (2011).

257. Samir, A. E. et al. Shear wave elastography in chronic kidney disease: A pilot experience in native kidneys. BMC Nephrol. 16, 1-9 (2015).

258. Ling, W. et al. Effects of vascularity and differentiation of hepatocellular carcinoma on tumor and liver stiffness: In vivo and in vitro studies. Ultrasound Med. Biol. 40, 739-746 (2014).

259. Cha, S. W. et al. Nondiseased liver stiffness measured by shearwave elastography a pilot study. J. Ultrasound Med. 33, 53-60 (2014).

260. Leal-Egaña, A. et al. Tuning liver stiffness against tumours: An in vitro study using entrapped cells in tumour-like microcapsules. J. Mech. Behav. Biomed. Mater. 9, 113-121 (2012).

261. Lee, D. H., Lee, J. M., Han, J. K. \& Choi, B. I. MR elastography of healthy liver 
parenchyma: Normal value and reliability of the liver stiffness value measurement. J. Magn. Reson. Imaging 38, 1215-1223 (2013).

262. Venkatesh, S. K., Wang, G., Teo, L. L. S. \& Ang, B. W. L. Magnetic resonance elastography of liver in healthy asians: Normal liver stiffness quantification and reproducibility assessment. J. Magn. Reson. Imaging 39, 1-8 (2014).

263. Gangadhar, K., Hippe, D. S., Thiel, J. \& Dighe, M. Impact of Image Orientation on Measurements of Thyroid Nodule Stiffness Using Shear Wave Elastography. J. Ultrasound Med. 35, 1661-1667 (2016).

264. Brezak, R., Hippe, D., Thiel, J. \& Dighe, M. K. Variability in stiffness assessment in a thyroid nodule using shear wave imaging. Ultrasound Q. 31, 243-249 (2015).

265. Lam, A. C. L., Pang, S. W. A., Ahuja, A. T. \& Bhatia, K. S. S. The influence of precompression on elasticity of thyroid nodules estimated by ultrasound shear wave elastography. Eur. Radiol. 26, 2845-2852 (2016).

266. Bahn, M. M. et al. Development and application of magnetic resonance elastography of the normal and pathological thyroid gland in vivo. J. Magn. Reson. Imaging 30, 1151-1154 (2009).

267. Pozzi, R. et al. Point shear-wave elastography in chronic pancreatitis: A promising tool for staging disease severity. Pancreatology 17, 905-910 (2017).

268. An, H., Shi, Y., Guo, Q. \& Liu, Y. Test-retest reliability of 3D EPI MR elastography of the pancreas. Clin. Radiol. 71, 1068.e7-1068.e12 (2016).

269. Kolipaka, A. et al. Magnetic resonance elastography of the pancreas: Measurement reproducibility and relationship with age. Magn. Reson. Imaging 42, 1-7 (2017).

270. Nenadic, I. et al. Noninvasive evaluation of bladder wall mechanical properties as a function of filling volume: Potential application in bladder compliance assessment. PLoS One 11, 1-14 (2016).

271. Matalia, J. et al. Correlation of Corneal Biomechanical Stiffness with Refractive Error and Ocular Biometry in a Pediatric Population. Cornea 36, 1221-1226 (2017).

272. Last, J. A., Thomasy, S. M., Croasdale, C. R., Russell, P. \& Murphy, C. J. Compliance profile of the human cornea as measured by atomic force microscopy. Micron 43, 1293-1298 (2012).

273. Jardeleza, M. S. R., Daly, M. K., Kaufman, J. D., Klapperich, C. \& Legutko, P. 
A. Effect of trypan blue staining on the elastic modulus of anterior lens capsules of diabetic and nondiabetic patients. J. Cataract Refract. Surg. 35, 318-323 (2009).

274. Yip, A. K. et al. Anisotropic traction stresses and focal adhesion polarization mediates topography-induced cell elongation. Biomaterials 181, 103-112 (2018).

275. Saruwatari, L. et al. Osteoblasts generate harder, stiffer, and more delaminationresistant mineralized tissue on titanium than on polystyrene, associated with distinct tissue micro- and ultrastructure. J. Bone Miner. Res. 20, 2002-2016 (2005).

276. Kalyan Phani, M., Kumar, A., Arnold, W. \& Samwer, K. Elastic stiffness and damping measurements in titanium alloys using atomic force acoustic microscopy. J. Alloys Compd. 676, 397-406 (2016).

277. Ingber, D. E. Cellular tensegrity: defining new rules of biological design that govern the cytoskeleton. J. Cell Sci. 104, 613-627 (1993).

278. Fabry, B. et al. Scaling the microrheology of living cells. Phys. Rev. Lett. 87, 1-4 (2001).

279. Stamenović, D. et al. Rheological behavior of living cells is timescale-dependent. Biophys. J. 93, 39-41 (2007).

280. Ingber, D. E., Wang, N. \& Stamenović, D. Tensegrity, cellular biophysics, and the mechanics of living systems. Reports Prog. Phys. 77, (2014). 